\title{
An Investigation of High-Cycle Fatigue Models for Metallic Structures Exhibiting Snap-Through Response
}

\author{
Adam Przekop* \\ National Institute of Aerospace, Hampton, VA, 23666 \\ Stephen A. Rizzi ${ }^{\dagger}$ \\ NASA Langley Research Center, Hampton, VA, 23681 \\ and \\ Karl A. Sweitzer ${ }^{\ddagger}$ \\ ITT, Rochester, NY 14606
}

\begin{abstract}
A study is undertaken to develop a methodology for determining the suitability of various high-cycle fatigue models for metallic structures subjected to combined thermal-acoustic loadings. Two features of this problem differentiate it from the fatigue of structures subject to acoustic loading alone. Potentially large mean stresses associated with the thermally preand post-buckled states require models capable of handling those conditions. Snap-through motion between multiple post-buckled equilibrium positions introduces very high alternating stress. The thermal-acoustic time history response of a clamped aluminum beam structure with geometric and material nonlinearities is determined via numerical simulation. A cumulative damage model is employed using a rainflow cycle counting scheme and fatigue estimates are made for 2024-T3 aluminum using various non-zero mean fatigue models, including Walker, Morrow, Morrow with true fracture strength, and MMPDS. A baseline zero-mean model is additionally considered. It is shown that for this material, the Walker model produces the most conservative fatigue estimates when the stress response has a tensile mean introduced by geometric nonlinearity, but remains in the linear elastic range. However, when the loading level is sufficiently high to produce plasticity, the response becomes more fully reversed and the baseline, Morrow, and Morrow with true fracture strength models produce the most conservative fatigue estimates.
\end{abstract}

\section{Nomenclature}

$\alpha$

$b, \sigma_{f}^{\prime}, \gamma$

$A_{1}, A_{2}, A_{3}, A_{4}$

$D$

$\varepsilon_{e}$

$\varepsilon_{p}$

E

$E[P]$

$G$

$H$

$N_{f}$
$=$ coefficient of thermal expansion

= material fatigue constants (Baseline, Morrow, and Walker Models)

$=$ material fatigue constants (MMPDS Model)

$=$ cumulative damage

$=$ elastic strain

$=$ plastic strain

$=$ Young's modulus

$=$ expected number of peaks per second

$=$ shear modulus

$=$ linear plastic hardening modulus

$=$ number of cycles to failure

* Research Scientist, AIAA Senior Member.

${ }^{\dagger}$ Aerospace Engineer, Structural Acoustics Branch, AIAA Associate Fellow.

‡ Chief Systems Engineer, Space Systems Division, AIAA Member. 


$\begin{array}{ll}p\left(\sigma_{\min }, \sigma_{\max }\right) & =\text { joint probability density function (PDF) of stress min and max values } \\ p\left(\sigma_{a r}, \sigma_{m}\right) & =\text { joint probability density function (PDF) of alternating and mean stress values } \\ \sigma_{a} & =\text { stress amplitude } \\ \sigma_{a r} & =\text { alternating stress } \\ \sigma_{e q} & =\text { equivalent stress } \\ \sigma_{m} & =\text { mean stress } \\ \sigma_{p} & =\text { plastic yielding stress } \\ \sigma_{\text {TFS }} & =\text { true stress at fracture } \\ R & \text { stress ratio }\left(\sigma_{\min } / \sigma_{\max }\right) \\ R F M\left(\sigma_{\min }, \sigma_{\max }\right) & =\text { rainflow matrix } \\ R F D\left(\sigma_{\min }, \sigma_{\max }\right) & =\text { rainflow damage matrix } \\ \rho & =\text { mass density } \\ T & =\text { time to failure } \\ \Delta T & =\text { temperature increment }\end{array}$

\section{Introduction}

FUTURE advanced aircraft and spacecraft structures will be exposed to increasingly severe operating P environments, including a combination of mechanical, pressure, acoustic, and thermal loads. These loading conditions can cause structures to respond in a nonlinear fashion and exhibit complex response characteristics, including snap-through behavior, as evidenced by several numerical ${ }^{1,2}$ and experimental ${ }^{3-5}$ studies. To help ensure structural integrity, an evaluation of relevant high cycle fatigue models is required to determine which are most suitable over the full range of response conditions.

Fatigue life prediction for structures subjected solely to high intensity acoustic loading was recently investigated by the authors. ${ }^{6}$ There it was found that the tensile mean stress associated with the nonlinear bending-membrane coupling can significantly reduce the estimated fatigue life. Fatigue life prediction of structures subject to combined loadings presents unique challenges because of an even wider range of stress ratios encountered. Consider for example, the measured strain response of a thermally buckled plate exposed to acoustic loading. ${ }^{3}$ In the absence of acoustic loading, the plate assumes one of two thermally buckled equilibrium positions when the temperature exceeds the critical value. In this condition, there exists a high static tensile mean strain on one side of the plate and a high compressive mean on the other. When low amplitude acoustic loading is applied at this condition, the vibratory strain is small compared to the static strain, as shown in the initial portions of Figure 1 and Figure 2. As the sound pressure level increases, the magnitude of oscillations increases until an intermittent (Figure 1) or persistent (Figure 2) snap-through response occurs. In the intermittent case, either side of the plate experiences both tensile and compressive mean strain, whilst the response becomes more fully reversed for the persistent condition. As the sound pressure level is subsequently decreased, the response stabilizes about either of the two positions. In addition to geometric nonlinearities, material nonlinearity may be present, which changes the global structural response and introduces compressive mean stress in locally plastic regions.

This paper develops a methodology for evaluating the suitability of various high-cycle fatigue models for metallic structures subject to thermal-acoustic environments. For this purpose, the thermal-acoustic response and fatigue of a flat clamped metallic beam is investigated. This simple structure is considered so that sufficiently long stress time histories may be obtained via numerical simulation of the nonlinear dynamic response without being too computationally taxing. Both geometric and material nonlinearities are accounted for in the simulation. Four distinct fatigue models accounting for the existence of a non-zero mean stress are investigated, namely Walker, Morrow, Morrow with true fracture strength, and Metallic Materials Properties Development and Standardization ${ }^{7}$ (MMPDS) models. Additionally, a baseline model neglecting the effect of non-zero mean is considered. The fatigue model behaviors as a function of mean stress are examined to understand why a particular model becomes more or less conservative than the others under a particular response regime. 


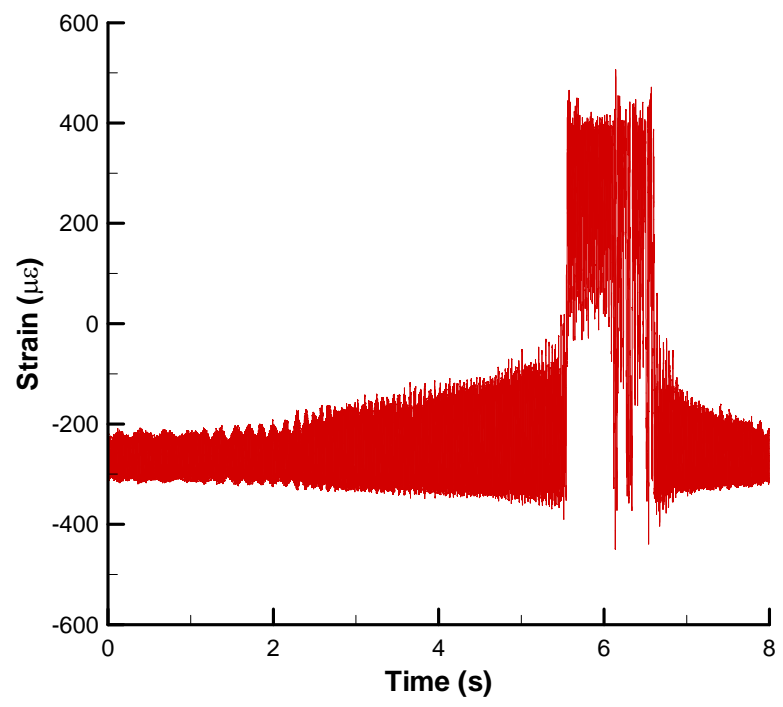

Figure 1: Measured strain response of thermally buckled plate undergoing intermittent snap-through. ${ }^{3}$

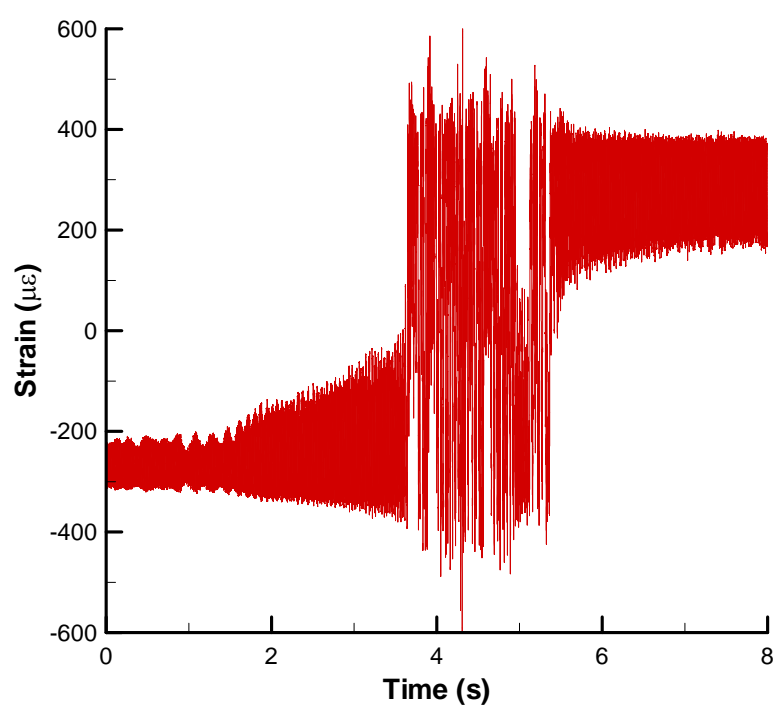

Figure 2: Measured strain response of thermally buckled plate undergoing persistent snap-through. ${ }^{3}$

\section{Thermal-Acoustic Nonlinear Response Analysis}

An aluminum beam structure previously considered ${ }^{2}$ served as the basis for the current investigation. The beam measured $0.4572 \mathrm{~m} \times 0.0254 \mathrm{~m} \times 2.286 \mathrm{~mm}(l \times w \times h)$, and had clamped boundary conditions at both ends, see Figure 3. Idealized elastic-plastic material properties with linear strain hardening were used, as shown in Figure 4. The elastic-plastic properties were based on empirical data and are given with the elastic modulus, shear modulus, plastic modulus, plastic yielding stress, mass density, and coefficient of thermal expansion as:

$$
\begin{array}{lll}
E=73.11 \mathrm{GPa}, & G=27.59 \mathrm{GPa}, & H=417 \mathrm{MPa}, \\
\sigma_{p}=400 \mathrm{MPa}, & \rho=2763 \frac{\mathrm{kg}}{\mathrm{m}^{3}}, & \alpha=22.32 \frac{\mu \mathrm{m} / \mathrm{m}}{{ }^{\circ} \mathrm{C}} .
\end{array}
$$

It was assumed that the plastic modulus and yield stress are the same in tension and compression. Material properties were assumed to be temperature independent because of the modest temperature range considered in this paper. Mass proportional damping of magnitude $14.52 \mathrm{~s}^{-1}$ was used in all the simulations. A failure criterion, e.g. ultimate tensile strength, was not imposed on the response modeling.

The beam response was analyzed with the finite element code ABAQUS. The finite element model consisted of 144 B21 beam elements $3.175 \mathrm{~mm}$ long. The B21 element allows single-plane bending and has one rotational and two translational degrees-of-freedom (DoF) at each node. The clamped boundary conditions were modeled by constraining the rotational and both translational (transverse and in-plane) DoFs at each end of the beam.

The ABAQUS/Explicit solution was used with an automatic time step adjustment, referred in ABAQUS as 'element-by-element'. ${ }^{8}$ This approach is known to yield a conservative time step increment. Time histories of the displacement, normal stress, and plastic strain, when applicable, were computed for each loading condition. The displacements were computed at the mid-span and quarter-span $(0.1143 \mathrm{~m})$ nodes. The stress and the plastic strain were computed in proximity to the clamped boundary and the quarter-span location since ABAQUS/Explicit computes only element strains and stresses. These locations corresponded to mid-element coordinates of $1.588 \mathrm{~mm}$ and $0.1159 \mathrm{~m}$, respectively. At each location, the normal stress and plastic strain were recovered at both the upper and lower element surfaces. The two locations along the span of the beam were chosen to provide insight into the stress response characteristics at differing bending to membrane stress ratios.

\section{A. Loading}

The beam was simultaneously subjected to a uniformly distributed random pressure loading, $p(t)$, and a uniformly distributed time invariant thermal loading, $\Delta T$, having zero through-the-thickness variation. Flat, bandlimited random pressure time histories were generated by summing equal amplitude random phase sine waves at a 
frequency resolution of $0.61 \mathrm{~Hz}$ in the frequency range $0-1500 \mathrm{~Hz} .{ }^{9}$ Three overall sound pressure levels were considered: 152, 158, and $170 \mathrm{~dB}$ (re: $20 \mu \mathrm{Pa}$ ). Each pressure time history was $60 \mathrm{~s}$ in duration.

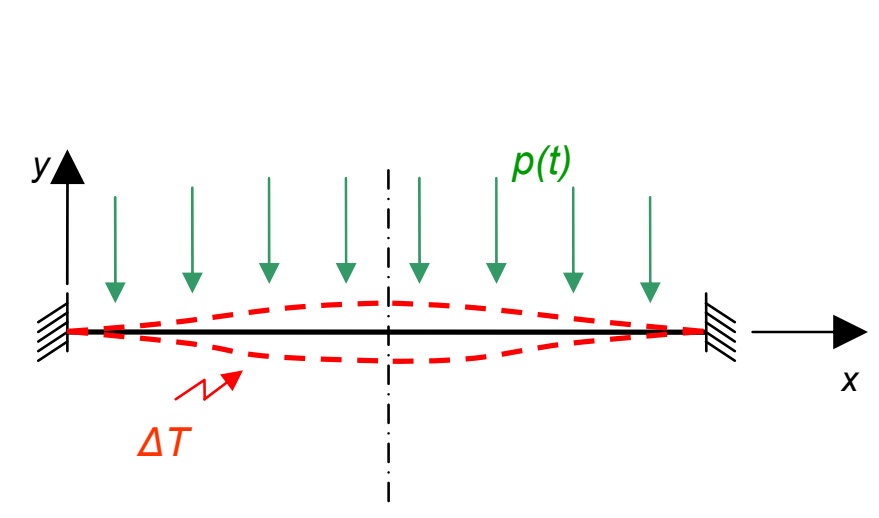

Figure 3: Beam under combined thermal and acoustic loading.

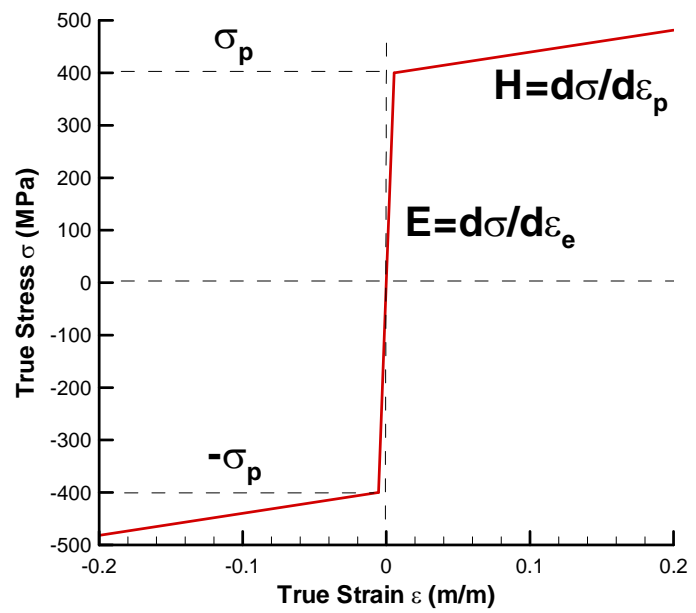

Figure 4: Elastic-plastic material properties.

To study the snap-through response, three thermal loading conditions were considered. An ambient temperature $(\Delta T=0)$ case served as an unstressed reference condition. A small temperature increment, $\Delta T=2.78^{\circ} \mathrm{C}\left(5^{\circ} \mathrm{F}\right)$, below the critical buckling temperature increment of $3.67^{\circ} \mathrm{C}\left(6.6^{\circ} \mathrm{F}\right)$ was used to investigate the thermally prebuckled response. For both unstressed reference and thermally pre-buckled conditions, a single neutral equilibrium position exists. Hence, no snap-through response was expected under any acoustic loading level.

The thermally post-buckled response was investigated with a temperature increment of $19.44^{\circ} \mathrm{C}\left(35^{\circ} \mathrm{F}\right)$. This condition had two non-zero symmetric equilibrium positions, as depicted by the red dashed line in Figure 3 . For this condition, increasing sound pressure level was previously shown to evolve the response from vibration around one of the positions, to intermittent snap-through and finally to persistent snap-through between the two equilibrium positions. ${ }^{2}$ For each non-zero temperature increment case, the thermal load was applied instantaneously at the beginning of each simulation. For the $19.44^{\circ} \mathrm{C}\left(35^{\circ} \mathrm{F}\right)$ temperature increment, application of the thermal loading in this manner produced a transient thermal buckling response. ${ }^{2}$

In the remainder of the paper, the combined load case is specified via the shorthand notation $x^{\circ} \mathrm{F} / y \mathrm{~dB}$, where $x$ is the temperature increment and $y$ is the random pressure level.

\section{B. Thermal-Acoustic Response Results}

The mid-span transverse displacement response and the total stress response at the clamped end of the thermally post-buckled beam $\left(\Delta T=35^{\circ} \mathrm{F}\right)$ are shown in Figure 5 and Figure 6, respectively, to demonstrate the evolution of the snap-through response. At the $152 \mathrm{~dB}$ level, relatively small amplitude oscillations about one of the thermally buckled equilibrium positions is indicated. The initial dynamic thermal buckling transient is visible in the initial response. At the $158 \mathrm{~dB}$ level, intermittent snap-through response is observed as the mid-span position oscillates between the two thermally buckled equilibrium positions. This behavior is akin to the intermittent snap-through response experimentally observed in the flat panel. ${ }^{3}$ Finally, a persistent snap-through response is shown at the $170 \mathrm{~dB}$ excitation level. A response matrix for the nine loading conditions is shown in Table 1, where $N$ designates no snap-through motion, $I$ designates intermittent snap-through motion, and $P$ designates persistent snap-through motion.

As seen in Figure 6, the response at $152 \mathrm{~dB}$ and $158 \mathrm{~dB}$ was below the plastic yield stress of $400 \mathrm{MPa}$. As will be shown in Section IV, the same was noted in the unstressed reference and pre-buckled conditions at these excitation levels. Material nonlinearity was only found to influence the dynamic response when the beam was excited at $170 \mathrm{~dB}$, for all three thermal loading conditions. To better understand the effect of plasticity on the dynamic response, a simulation was performed at the $35^{\circ} \mathrm{F} / 170 \mathrm{~dB}$ loading condition using linear elastic material properties only. The identical pressure time history was applied as the simulation using elastic-plastic material properties. Stress and plastic strain time histories for both simulations are superimposed in Figure 7. The two stress responses are identical for the initial $0.15 \mathrm{~s}$ or so, deviating thereafter following a stress excursion above the plastic yield stress. The point at which they deviate is also marked by a non-zero plastic strain in the elastic-plastic material model simulation. Beyond $0.15 \mathrm{~s}$, the elastic material model response continues to oscillate in a symmetric fashion, 
while the elastic-plastic material model response oscillates mostly about a non-zero mean stress caused by the residual plastic strain. The amount of plastic strain varies with time, as subsequent high loading events are encountered. The stress response, as shown in Figure 8, exhibits an asymptotic behavior. The maximum stress is limited by the amount of peak plastic strain, which increases over time as a result of new high loading events. The rate at which these events occur diminishes with time and is governed by the standard deviation of the random loading. The onset of plasticity was limited only to a portion of the beam near the clamped ends. While the exact extent of the plastic region was not investigated, it was determined that yielding did not occur at the quarter-span.

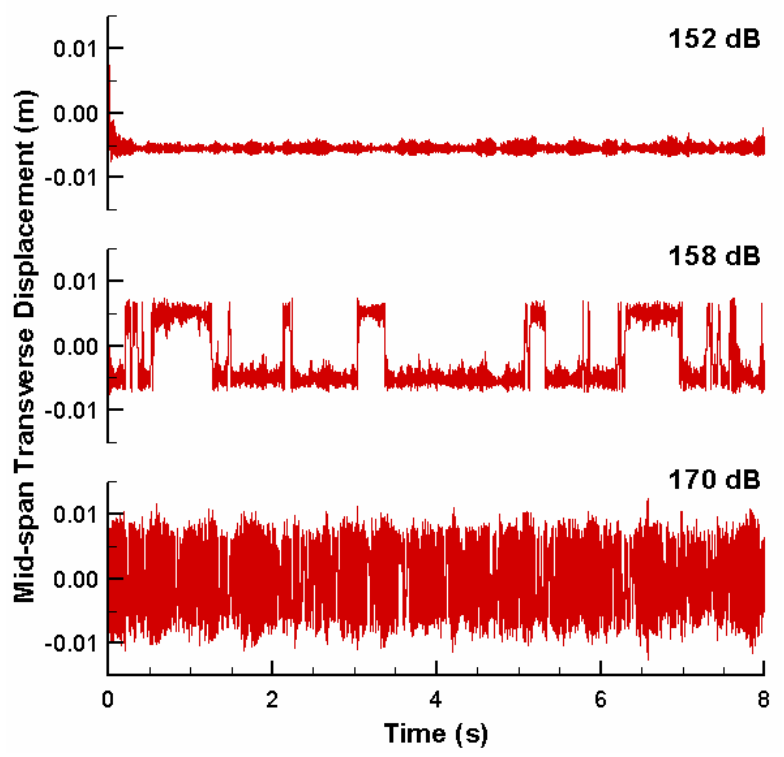

Figure 5: Transverse displacement response at the midspan of the thermally post-buckled beam.

Table 1: Response matrix indicating no snap-through $(N)$, intermittent snap-through $(I)$, and persistent snapthrough $(P)$.

\begin{tabular}{|c|c|c|c|}
\hline$\Delta T^{S P L}$ & $152 \mathrm{~dB}$ & $158 \mathrm{~dB}$ & $170 \mathrm{~dB}$ \\
\hline 0 & $N$ & $N$ & $N$ \\
\hline $\begin{array}{c}2.78^{\circ} \mathrm{C} \\
\left(5^{\circ} \mathrm{F}\right)\end{array}$ & $N$ & $N$ & $N$ \\
\hline $\begin{array}{c}19.44^{\circ} \mathrm{C} \\
\left(35^{\circ} \mathrm{F}\right)\end{array}$ & $N$ & $I$ & $P$ \\
\hline
\end{tabular}

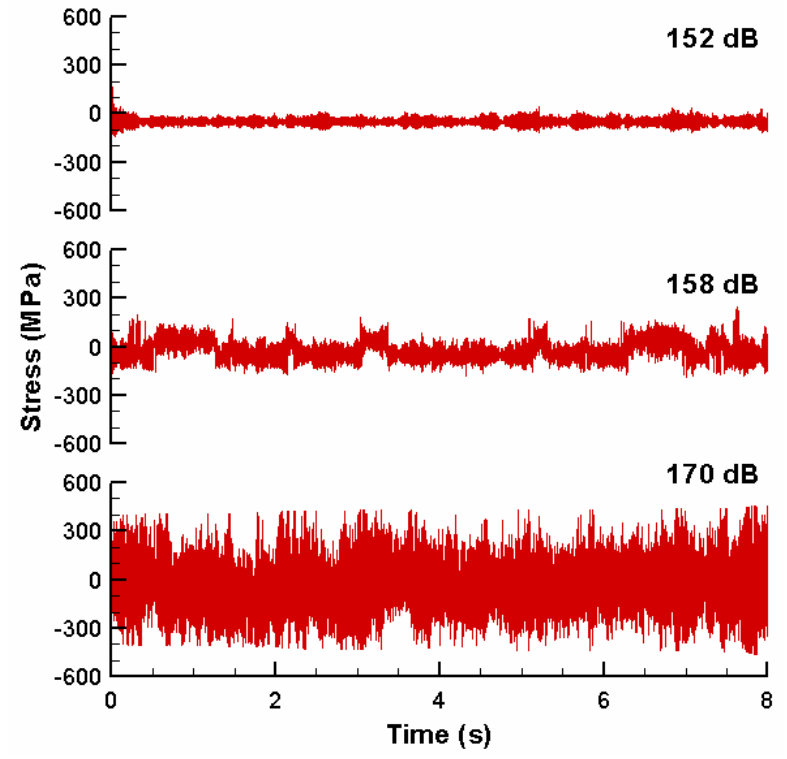

Figure 6: Total stress response at the clamped end of the thermally post-buckled beam.

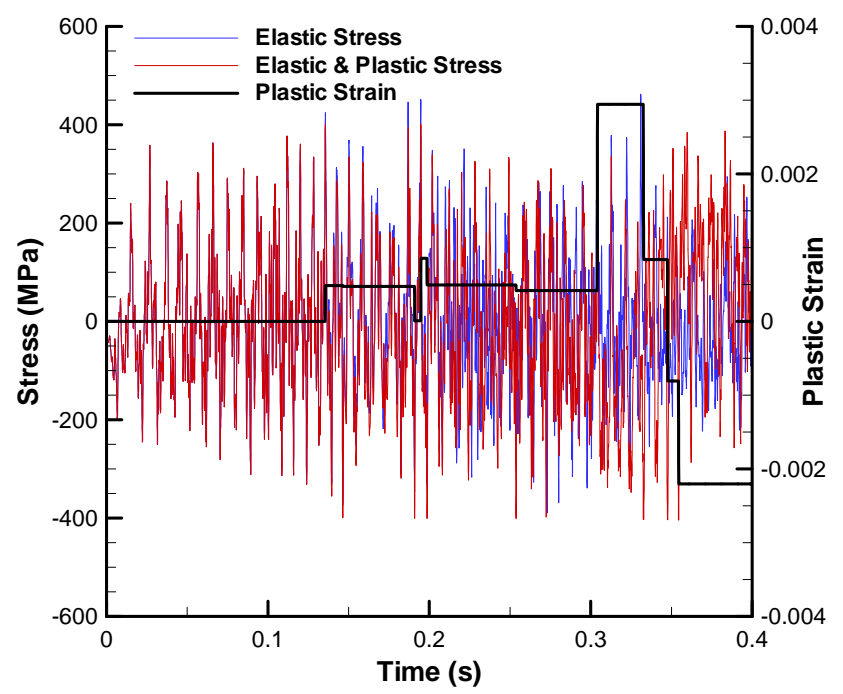

Figure 7: Stress and plastic strain time history for the $35^{\circ} \mathrm{F} / 170 \mathrm{~dB}$ condition at the clamped end.

The effect of plasticity can also be observed in the stress power spectral density (PSD) at the clamped end. Shown in Figure 9 is the stress PSD obtained from the stress response computed using linear elastic and elasticplastic material models. It is seen that the high frequency response characteristics are not significantly altered as a 
result of plasticity. However, the zero-frequency response shows a substantial increase in compressive mean stress due to plasticity. The effect on the fatigue life will be explored further in Section IV.

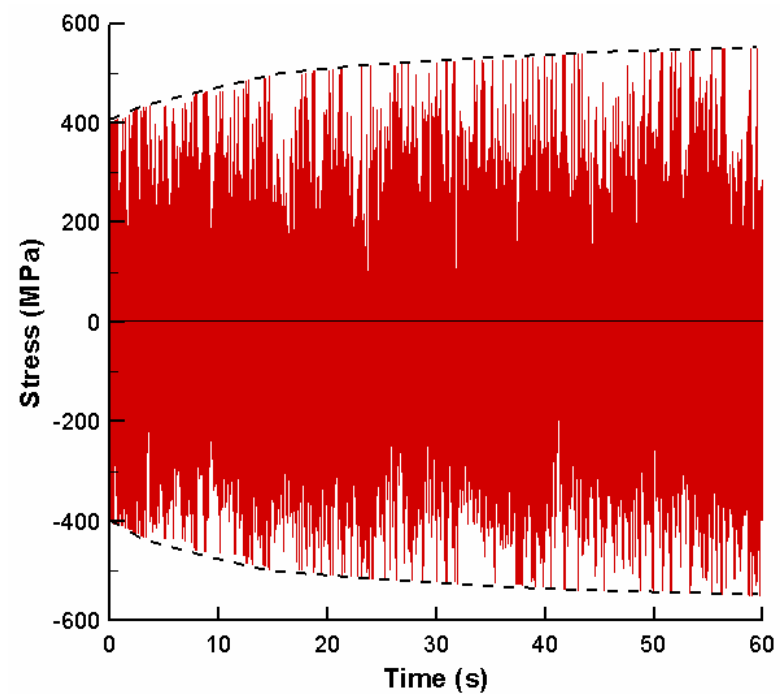

Figure 8: Clamped end stress time history for the $35^{\circ} \mathrm{F} / 170 \mathrm{~dB}$ condition.

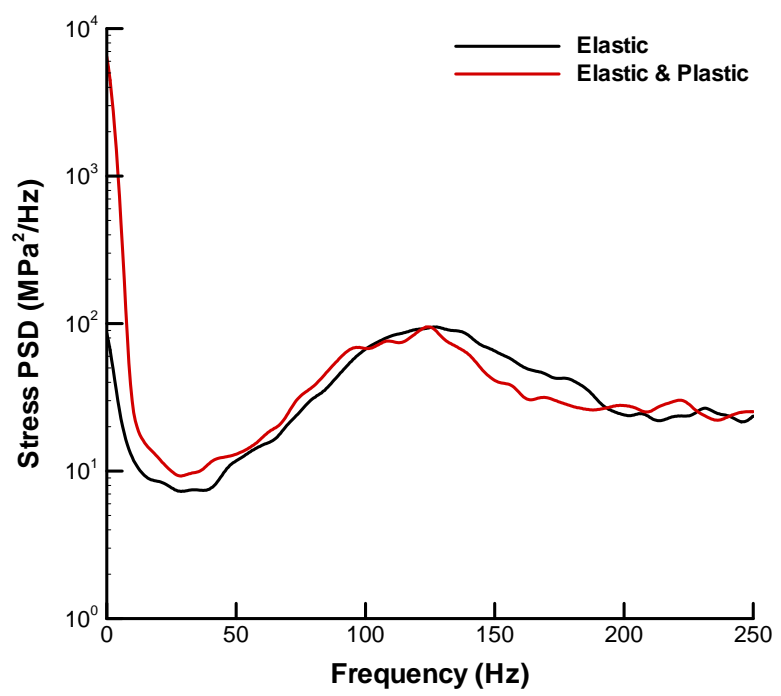

Figure 9: Clamped end stress PSD for the $35^{\circ} \mathrm{F} / 170 \mathrm{~dB}$ condition.

\section{Random Fatigue Analysis Models}

For a constant amplitude, zero-mean stress response, the stress-life $(S-N)$ curve relates the cycles to failure, $N_{f}$, to the fully reversed alternating stress, $\sigma_{a r}$, via the power law

$$
\sigma_{a r}=A N_{f}^{b}
$$

where $A=\sigma_{f}^{\prime} 2^{b}$, and $\sigma_{f}^{\prime}$ and $b$ are material properties determined from tests performed under zero-mean stress. The fatigue life can then be determined from

$$
N_{f}=\left(\frac{\sigma_{a r}}{A}\right)^{1 / b} .
$$

For conditions having a non-zero mean stress, $\sigma_{m}$, a number of models are available, see Dowling. ${ }^{10}$ In this paper, we consider five models; the baseline zero mean model, Equation (2), two Morrow models, and two Walker models. The stress amplitude $\sigma_{a}$ and mean stress may be expressed as

$$
\begin{gathered}
\sigma_{a}=\frac{\sigma_{\max }-\sigma_{\min }}{2}=\frac{\sigma_{\max }}{2}(1-R) \\
\sigma_{m}=\frac{\sigma_{\max }+\sigma_{\min }}{2}=\frac{\sigma_{\max }}{2}(1+R)
\end{gathered}
$$

where the stress ratio $R$ is given by

$$
R=\frac{\sigma_{\min }}{\sigma_{\max }} .
$$

For fully reversed loadings, $R=-1, \sigma_{a r}=\sigma_{\max }$ and $\sigma_{m}=0$.

In the standard Morrow model, the number of cycles to failure is

$$
N_{f m}=\left[\sigma_{a} / A\left(1-\frac{\sigma_{m}}{\sigma_{f}^{\prime}}\right)\right]^{1 / b} .
$$


For nonferrous materials, a modification using the true stress at fracture $\sigma_{T F S}$, referred to as Morrow TFS in this paper, is

$$
N_{f m T F S}=\left[\sigma_{a} / A\left(1-\frac{\sigma_{m}}{\sigma_{T F S}}\right)\right]^{1 / b}
$$

Aluminum 2024-T3 material properties used in the baseline and Morrow models are: ${ }^{10} \sigma_{f}^{\prime}=1602 \mathrm{MPa}, b=-0.154$, and $\sigma_{\text {TFS }}=610 \mathrm{MPa}$.

In the standard Walker model, the number of cycles to failure is

$$
N_{f w}=\left[\frac{\sigma_{\max }}{A_{w}}\left(\frac{1-R}{2}\right)^{\gamma}\right]^{1 / b_{w}}
$$

where $A_{w}=\sigma_{f w}^{\prime} 2^{b_{w}}$ and $\sigma_{f w}^{\prime}, b_{w}$, and $\gamma$ are material properties determined from tests performed over a range of stress ratios $R$. Material properties used in the Walker model are: ${ }^{10} \sigma_{f w}^{\prime}=1772 \mathrm{MPa}, b_{w}=-0.163$, and $\gamma=0.460$. It should be noted that the Walker model material data is not considered valid for $R<-2$, hence $N_{f w}$ is not calculated for stress ratios in that range.

A modified version of the Walker equation, used in the MMPDS ${ }^{7}$ (the replacement for MIL-HDBK-5), is based on the stress ratio $R$ and an equivalent stress $\sigma_{e q}$, where

$$
\begin{aligned}
\log \left(N_{f 5}\right) & =A_{1}+A_{2} \log \left(\sigma_{e q}-A_{4}\right) \\
\sigma_{e q} & =\sigma_{\text {max }}(1-R)^{A_{3}}
\end{aligned} .
$$

The term $A_{4}$ represents the fatigue limit stress or endurance limit. Section 9.6.1.4 of MMPDS ${ }^{7}$ gives a thorough discussion of Equation (8). It should be noted that the endurance limit is not present in the baseline, Morrow, Morrow TFS or standard Walker models. The material constants used in Equation (8), expressed for stress in ksi, are: ${ }^{7} A_{1}=11.1, A_{2}=-3.97, A_{3}=0.56$, and $A_{4}=15.8$. Because the origin of the MMPDS material property data is different than the other models, differences in fatigue estimates may be partially attributable to material properties, and not just the model itself.

The Palmgren-Miner linear cumulative damage rule ${ }^{11}$ is typically used for variable amplitude loading and assumes that the damage, $D$, caused by stress cycles for one load amplitude can be calculated and added to damage caused by stress cycles in another load amplitude, or

$$
D=\sum_{i} \frac{N_{i}}{\left(N_{f}\right)_{i}}
$$

where $N_{i}$ are the number of cycles, and $\left(N_{f}\right)_{i}$ are the number of cycles to failure for load case $i$.

\section{A. Random Fatigue}

For random response, it is convenient to recast Equation (9) in the form

$$
E[D]=E[P] T \int_{-\infty}^{\infty} \int_{-\infty}^{\infty} N_{f}\left(\sigma_{\min }, \sigma_{\max }\right)^{-1} p\left(\sigma_{\min }, \sigma_{\max }\right) d \sigma_{\min } d \sigma_{\max }
$$

where $E[P]$ is the expected number of peaks per second, $T$ is the analysis period, and $p\left(\sigma_{\min }, \sigma_{\max }\right)$ is the joint PDF of stress minimum and maximum values. In terms of amplitude and mean stress

$$
E[D]=E[P] T \int_{-\infty}^{\infty} \int_{0}^{\infty} N_{f}\left(\sigma_{a}, \sigma_{m}\right)^{-1} p\left(\sigma_{a}, \sigma_{m}\right) d \sigma_{a} d \sigma_{m} .
$$


The dependency of $N_{f}$ on $\sigma_{m}$ and $\sigma_{a}$, or on $\sigma_{\min }$ and $\sigma_{\max }$, is determined by the particular model used, e.g. zero-mean, Morrow, or Walker.

It was shown ${ }^{12}$ that $p\left(\sigma_{\min }, \sigma_{\max }\right)$ can be estimated from the rainflow matrix (RFM)

$$
\frac{1}{N_{R F}} \sum_{-\infty}^{\infty} \sum_{-\infty}^{\infty} R F M\left(\sigma_{\min }, \sigma_{\max }\right)=\int_{-\infty}^{\infty} \int_{-\infty}^{\infty} p\left(\sigma_{\min }, \sigma_{\max }\right) d \sigma_{\min } d \sigma_{\max }
$$

where $N_{R F}$ are the number of rainflow cycles. The RFM is a two-dimensional histogram of rainflow ranges. In this paper, the RFM was obtained using the Wave Analysis for Fatigue and Oceanography (WAFO) Matlab toolbox for analysis of random waves and loads. ${ }^{13}$ The archetypal WAFO RFM is shown in Figure 10. Only half of the RFM is used because the minimum stress can never be greater than the maximum stress. For example, a stress range pair having a zero minimum stress must have a maximum stress greater than zero. Lines are drawn along constant values of the stress ratio $R$ to give insight into the distribution of ranges. Constant amplitude conditions, when $\sigma_{\max }-\sigma_{\min }=$ constant, are found along diagonals of positive slope. Constant mean stress ranges, when $\sigma_{\max }+\sigma_{\min }=$ constant, are found along diagonals of negative slope.

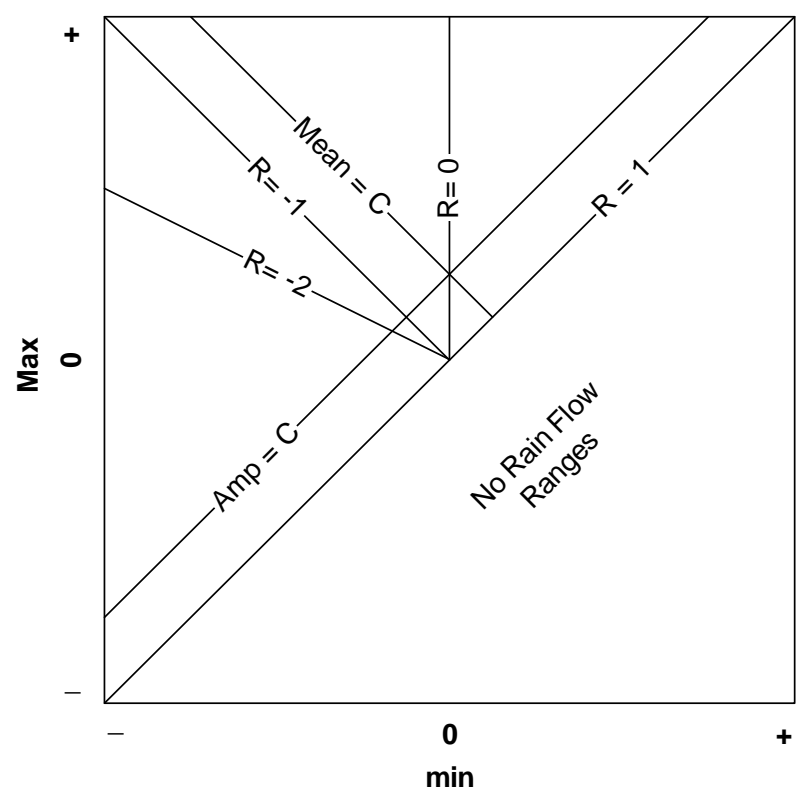

Figure 10: WAFO rain flow matrix. ${ }^{12}$

For a finite record of duration $T_{r}, E[P] \approx N_{R F} / T_{r}$. This is approximate because the discrete RFM disregards cycles that have a range less than the bin width. This is considered acceptable given the very low damage from these approximately zero amplitude cycles. Substitution of Equation (12) into (10) then yields

$$
E[D]=\frac{T}{T_{r}} \sum_{-\infty}^{\infty} \sum_{-\infty}^{\infty} \frac{R F M\left(\sigma_{\min }, \sigma_{\max }\right)}{N_{f}\left(\sigma_{\min }, \sigma_{\max }\right)}=\frac{T}{T_{r}} \sum_{-\infty}^{\infty} \sum_{-\infty}^{\infty} R F D\left(\sigma_{\min }, \sigma_{\max }\right)
$$

where $\operatorname{RFD}\left(\sigma_{\min }, \sigma_{\max }\right)$ is the two-dimensional rainflow damage matrix. Median failure occurs when $E[D]=1$, giving the estimated median fatigue life $T$ as

$$
T=T_{r} / \sum_{-\infty}^{\infty} \sum_{-\infty}^{\infty} \frac{R F M\left(\sigma_{\min }, \sigma_{\max }\right)}{N_{f}\left(\sigma_{\min }, \sigma_{\max }\right)} .
$$

Note that since damage is calculated for each bin of the RFM, the quantities in Equations (13) and (14) vary with each cycle. 
An understanding of how the various models calculate damage for each bin of the RFM is essential for interpreting the fatigue results that follow. Plotted in Figure 11 - Figure 14 are the cycles to failure for the baseline, Morrow, Morrow TFS, and MMPDS models, normalized by the cycles to failure for the standard Walker model. The number of cycles to failure were computed directly from Equations (2), (5), (6), (7), and (8), using minimum and maximum stress pairs over the range of interest. The figures are therefore not specific to a particular response, but are applicable to any condition. The Walker model was selected for the normalization because it was found to be the most conservative for the majority of conditions considered. This finding will be discussed in further detail in Section IV. Superimposed on each plot is a line for $R=-1$. The cutoff in the Walker model below $R=-2$ is evident in each plot. For the baseline model in Figure 11, the cycles to failure ratio is largely greater than 1 when the mean stress is tensile (to the right of $R=-1$ ). A ratio greater than 1 is indicative of a non-conservative estimate relative to the Walker model. In the vicinity of $R=-1$ and for compressive mean stress (to the left of $R=-1$ ), the baseline model is more conservative than the Walker model. The ratio for the Morrow model is shown in Figure 12. Like the baseline model, the Morrow model is non-conservative for a tensile mean stress and more conservative for a compressive mean stress. The Morrow model is seen to be more conservative than the baseline model in the presence of a tensile mean stress. The Morrow TFS ratio is shown in Figure 13 to exhibit similar characteristics as the Morrow model in the highlighted region. This region encompasses most of the cases considered, except for the $170 \mathrm{~dB}$ conditions at the clamped end. For the high stress ranges associated with the latter conditions, the Morrow TFS model becomes more conservative than the Walker model. Particularly noteworthy is that the Morrow TFS model is more conservative than the Morrow and baseline models for high stress amplitudes along $R=-1$. Finally, the MMPDS ratio is shown in Figure 14. For sufficiently high stress amplitudes, the MMPDS model becomes much less conservative than the Walker model along $R=-1$. The peculiar behavior for small stress amplitudes is attributable to the endurance limit present in the MMPDS model.

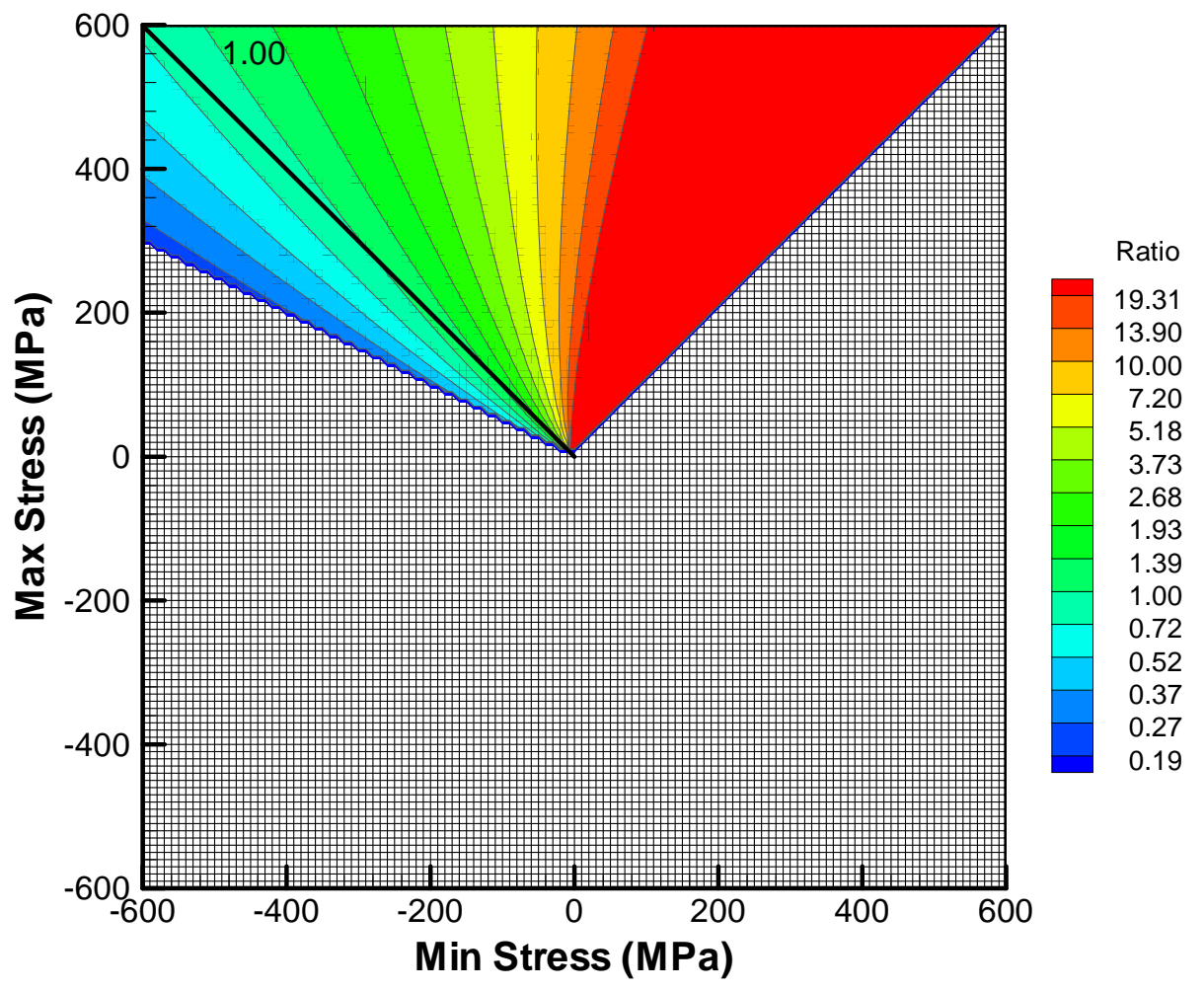

Figure 11: Baseline model cycles to failure normalized by Walker model cycles to failure $\left(N_{f} / N_{f w}\right)$. 


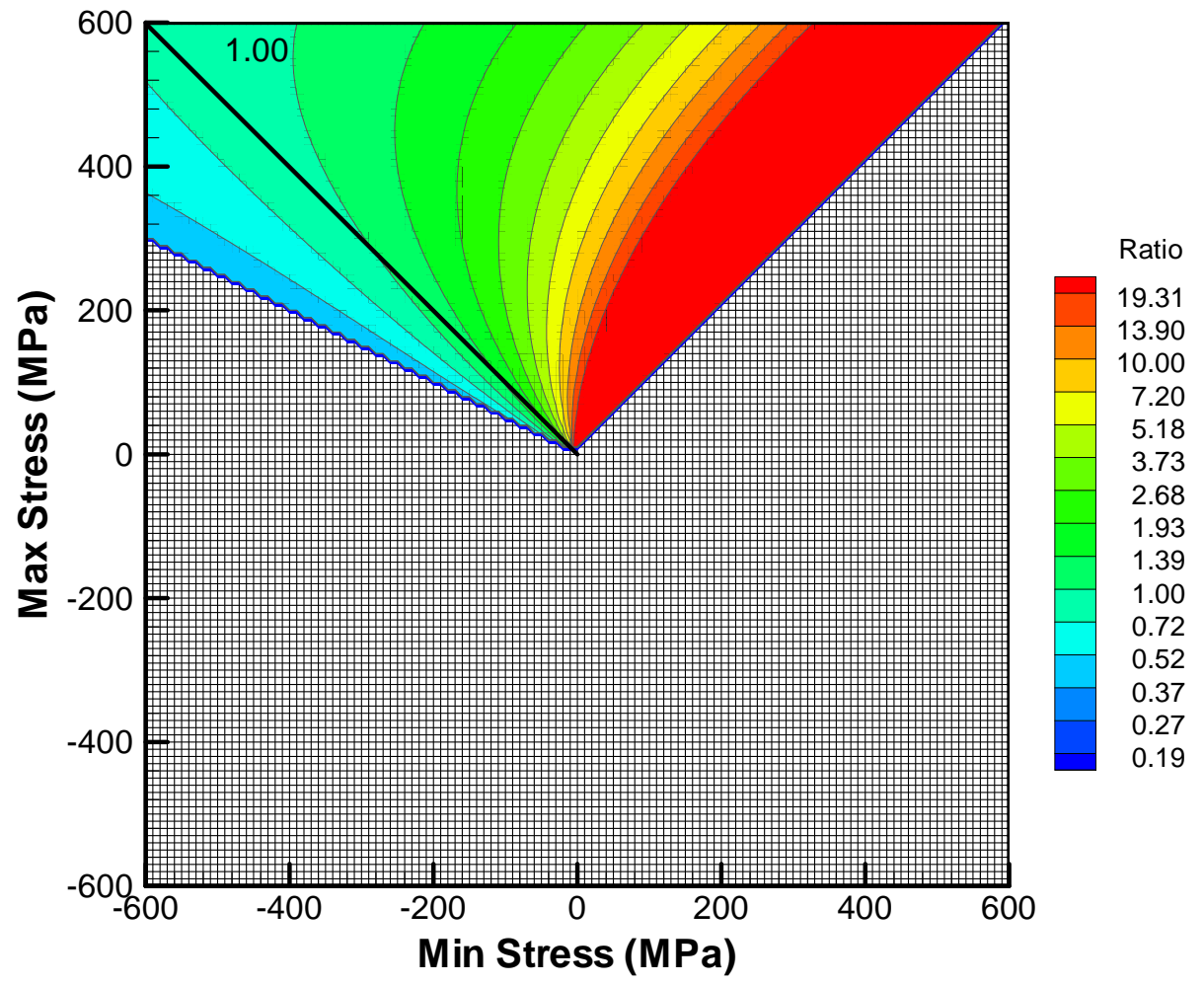

Figure 12: Morrow model cycles to failure normalized by Walker model cycles to failure $\left(N_{f m} / N_{f w}\right)$.

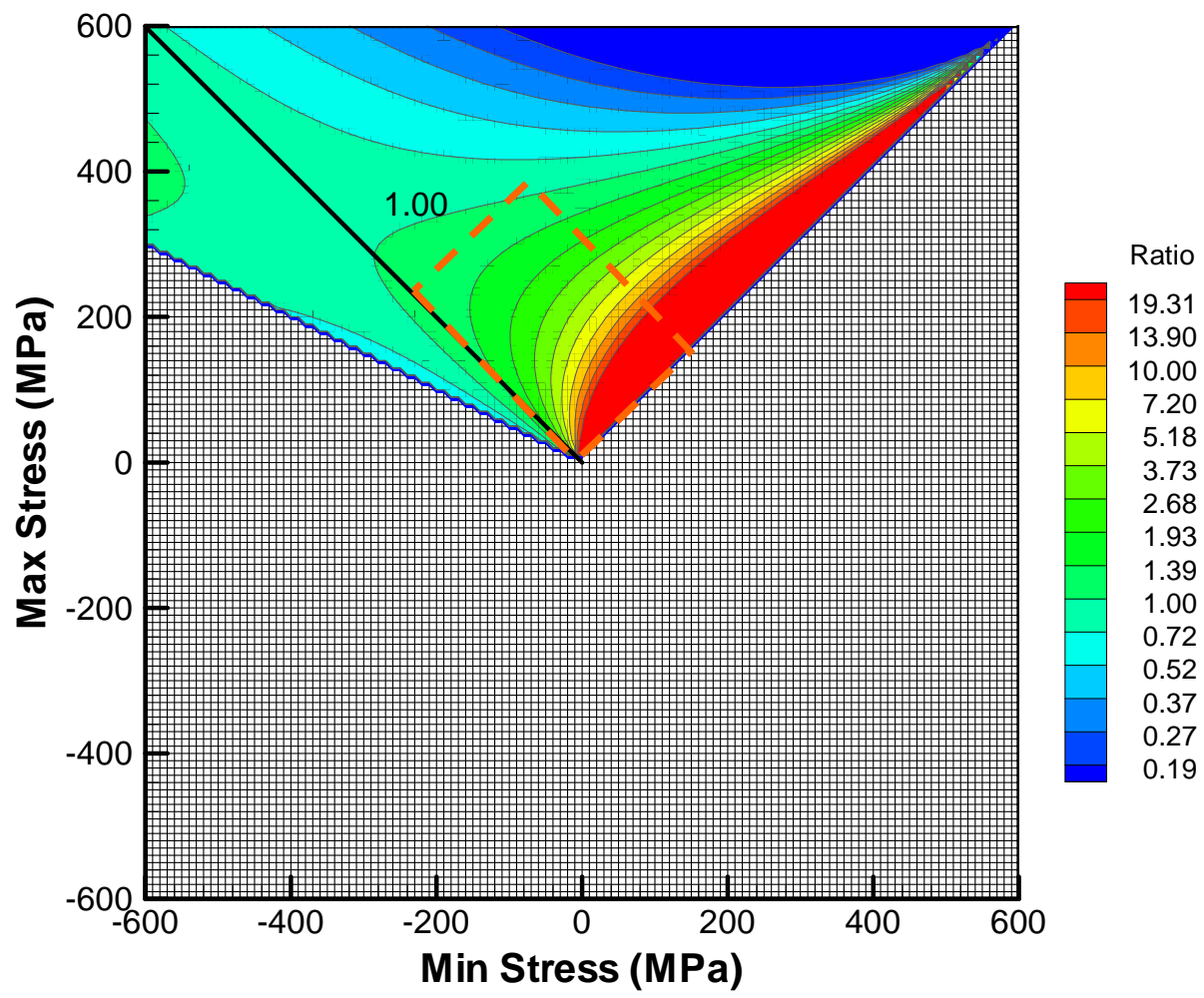

Figure 13: Morrow TFS model cycles to failure normalized by Walker model cycles to failure ( $N_{f m T F S} / N_{f w}$ ). 


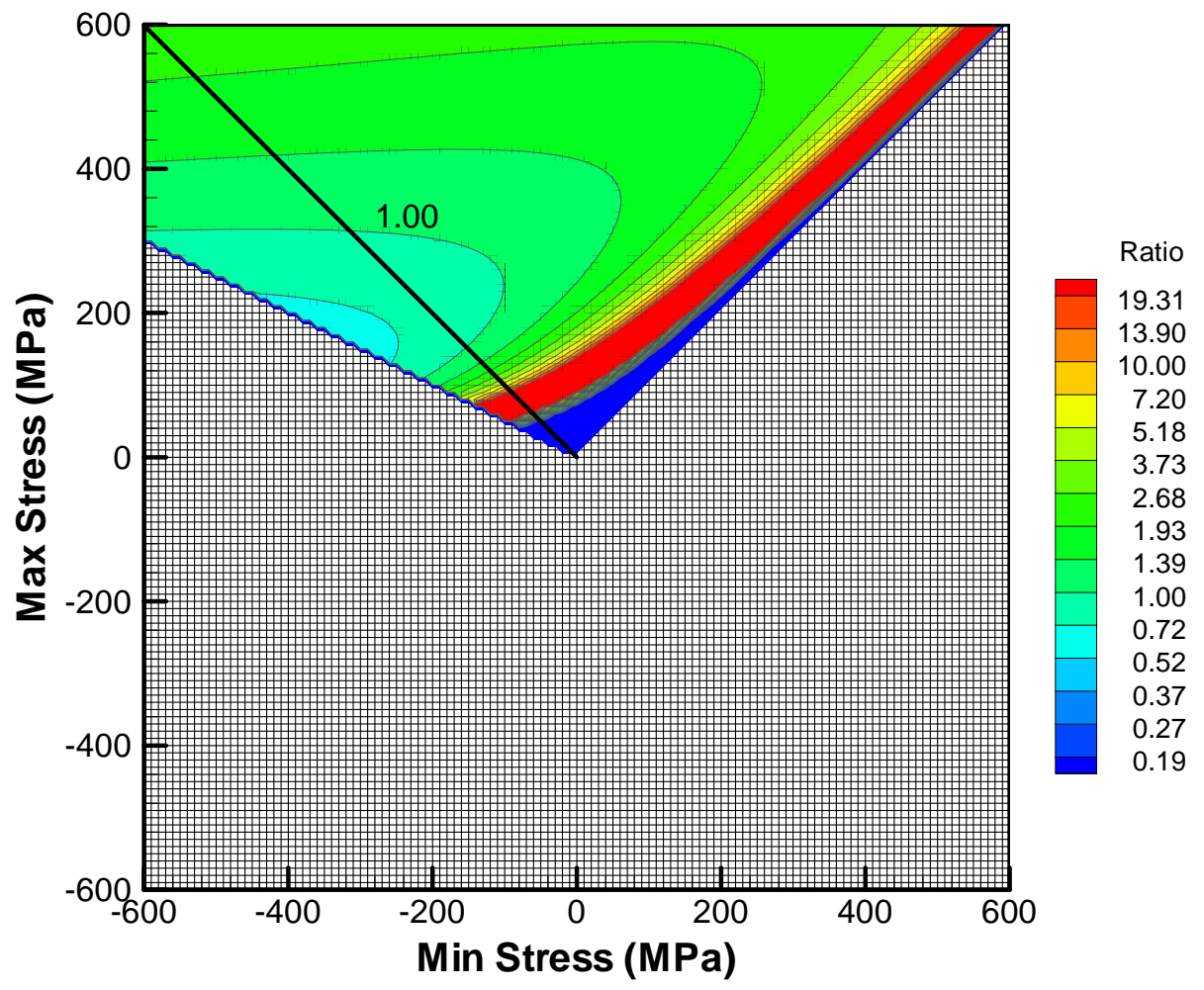

Figure 14: MMPDS model cycles to failure normalized by Walker model cycles to failure ( $N_{f 5} / N_{f w}$ ).

\section{Fatigue Results}

Studies were first conducted to verify that a sufficient quantity of data were available to generate converged fatigue estimates. Fatigue estimates were then computed using the aforementioned models to determine which tended to be most and least conservative under each response condition, i.e., unstressed reference, pre-buckled, and thermally post-buckled. Finally, the effect of localized material nonlinearity was studied to quantify which factor affects fatigue life more; the plastic zone itself or changes in the structural dynamics due to a portion of the structure having undergone plastic deformation.

\section{A. Convergence Study}

The goal of the analysis was to estimate time (or number of cycles) to failure with an allowable random error, $\operatorname{err}_{N f}$, of approximately $10 \%$. The power law relationship between stress and number of cycles to failure, Equation

(1), was used to estimate the random error in the standard deviation of stress response $\mathrm{err}_{\sigma}$

$$
1+e r r_{\sigma}=\left(1+e r r_{N f}\right)^{-b}
$$

which for this study is approximately $2 \%$. This value of $\mathrm{err}_{\sigma}$ was used to set the simulation duration to $60 \mathrm{~s}^{14}$

The initial $1 \mathrm{~s}$ segment containing the startup transient was removed from each simulation block, leaving a $59 \mathrm{~s}$ block of fully developed response for use in ensuing fatigue analyses. The convergence was studied by dividing the simulation results into sub-blocks and computing the time to failure estimates as each additional sub-block was included in the ensemble. In seven of the nine conditions studied, a single $59 \mathrm{~s}$ block was found to be sufficient for converged fatigue estimates. A typical plot of this convergence study is shown in Figure 15. Note that the order of the time to failure estimates, based on the different damage models, does not change and that the desired $~ 10 \%$ error for time to failure has been achieved. For the case shown, the stress was below the endurance limit of the MMPDS model, so those results are not shown.

The two cases, $35^{\circ} \mathrm{F} / 152 \mathrm{~dB}$ and $35^{\circ} \mathrm{F} / 158 \mathrm{~dB}$, did not tend to converge for the baseline simulation period of $59 \mathrm{~s}$, so nine additional simulations were run to determine the time required to reach a converged estimate of time to failure. A convergence plot for the $35^{\circ} \mathrm{F} / 158 \mathrm{~dB}$ case is shown in Figure 16 . In both the $35^{\circ} \mathrm{F} / 152 \mathrm{~dB}$ and 
$35^{\circ} \mathrm{F} / 158 \mathrm{~dB}$ cases it took approximately $200 \mathrm{~s}$ to converge to a stable estimate with the desired $\sim 10 \%$ error for time to failure. Again, the order of estimate based on damage model did not change as the time to failure converges.

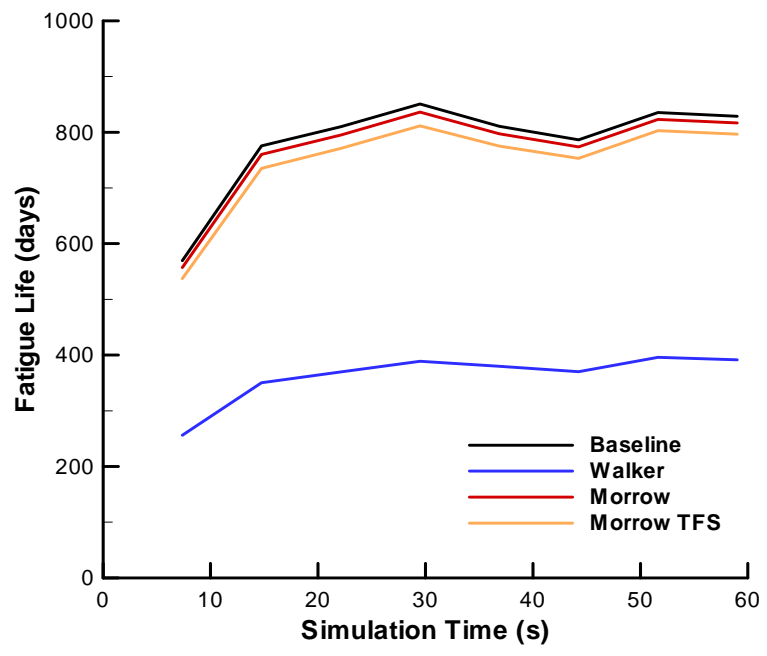

Figure 15: Convergence study for a single $59 \mathrm{~s}$ simulation at the $5^{\circ} \mathrm{F} / 152 \mathrm{~dB}$ loading condition.

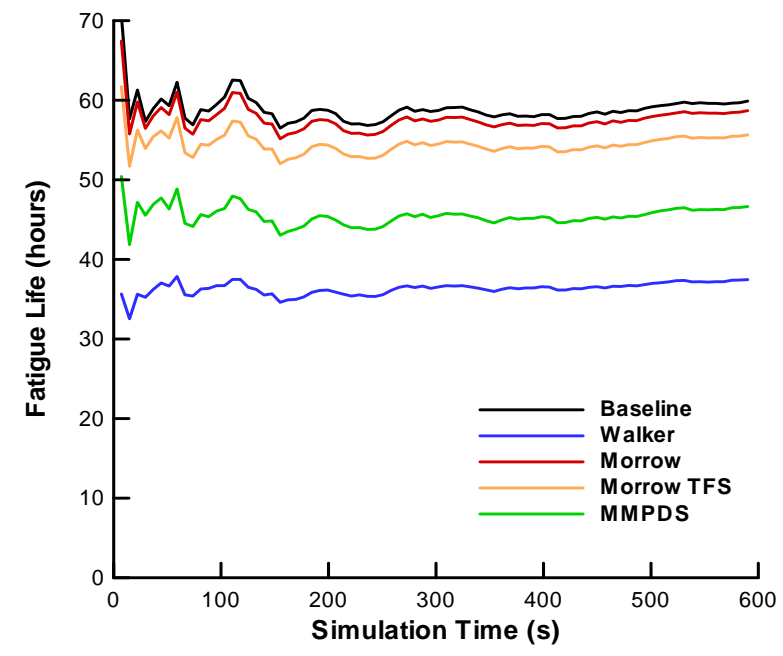

Figure 16: Convergence study for ten 59 s simulations at the $35^{\circ} \mathrm{F} / 158 \mathrm{~dB}$ loading condition.

\section{B. Unstressed Reference and Pre-Buckled Conditions}

Fatigue estimates at the clamped end are first considered, as the stresses there are highest and will dictate the fatigue life of the structure as a whole. The $0^{\circ} \mathrm{F} / 152 \mathrm{~dB}$ loading condition exhibits the effect of geometric nonlinearity without the effect of material nonlinearity. The RFM is shown in Figure 17. For small stress amplitudes, the majority of cycle counts are approximately evenly distributed about $R=-1$. However higher stress amplitudes exhibit a tensile mean which is attributable to membrane stretching as the structure undergoes large deformation. The effect of this tensile mean on the accumulated damage is apparent in Figure 18 and Figure 19, for the Walker and Morrow TFS models, respectively. As shown in Figure 11 - Figure 13, the Walker model accumulates more damage for high stress cycles with tensile mean than the Morrow TFS, Morrow, and baseline models in this stress range. The stress range for this condition is below the endurance limit of the MMPDS model. The fact that damage accumulation for the Walker model is cutoff for $R<-2$ is of little consequence, as the damage associated with these cycles is small. The fatigue life estimates for this condition are shown in Figure 20. The Walker model is clearly the most conservative. However, it should be noted that all estimates are within a factor of three. In this and similar figures that follow, dashed lines were used to highlight the trends. Interpolation along these lines to establish intermediate values is not valid.

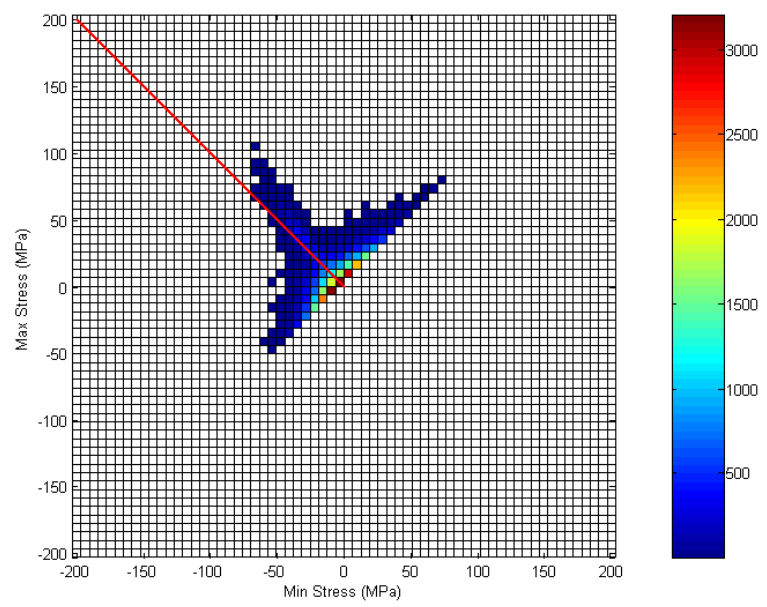

Figure 17: RFM for the $0^{\circ} \mathrm{F} / 152 \mathrm{~dB}$ condition.

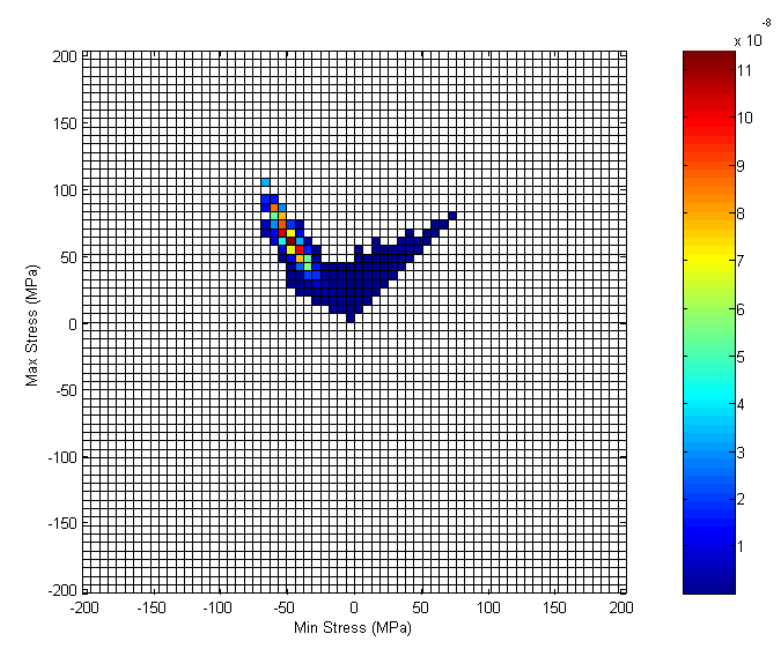

Figure 18: Walker model RFD for $0^{\circ} \mathrm{F} / 152 \mathrm{~dB}$. 


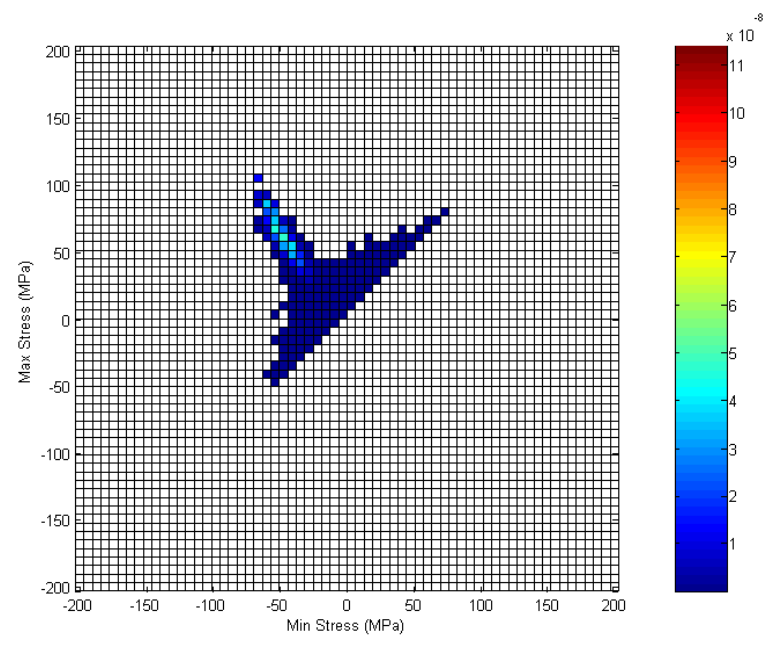

Figure 19: Morrow TFS model RFD for $0^{\circ} \mathrm{F} / 152 \mathrm{~dB}$.

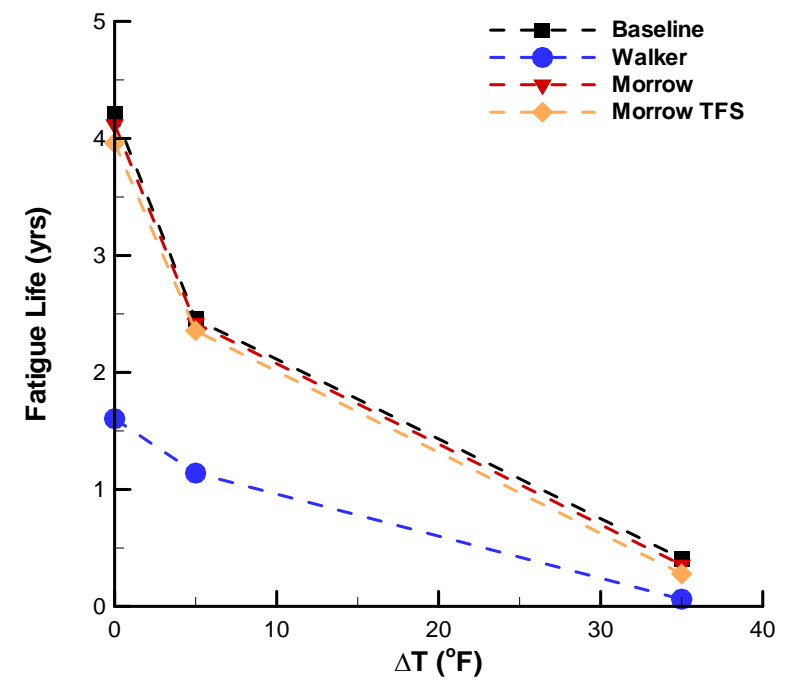

Figure 20: Clamped end fatigue estimates at $152 \mathrm{~dB}$.

As the acoustic excitation level is increased from $152 \mathrm{~dB}$ to $158 \mathrm{~dB}$, the effect of geometric nonlinearity is increased, while the stress remains below the plastic limit. The corresponding RFM is shown in Figure 21. For the reasons cited for the $0^{\circ} \mathrm{F} / 152 \mathrm{~dB}$ conditions, the Walker model remains the most conservative of all models, as shown in Figure 22. The stresses for the $0^{\circ} \mathrm{F} / 158 \mathrm{~dB}$ condition exceed the endurance limit of the MMPDS model.

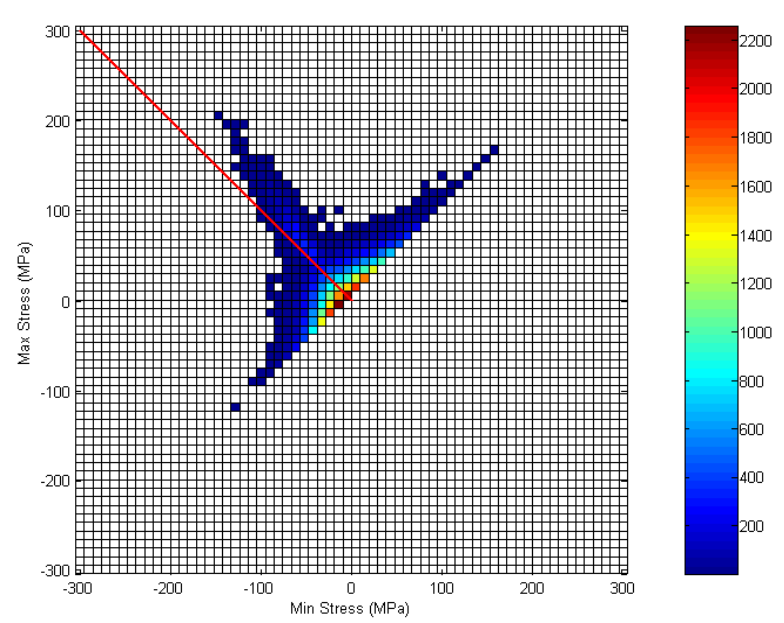

Figure 21: RFM for the $0^{\circ} \mathrm{F} / 158 \mathrm{~dB}$ condition.

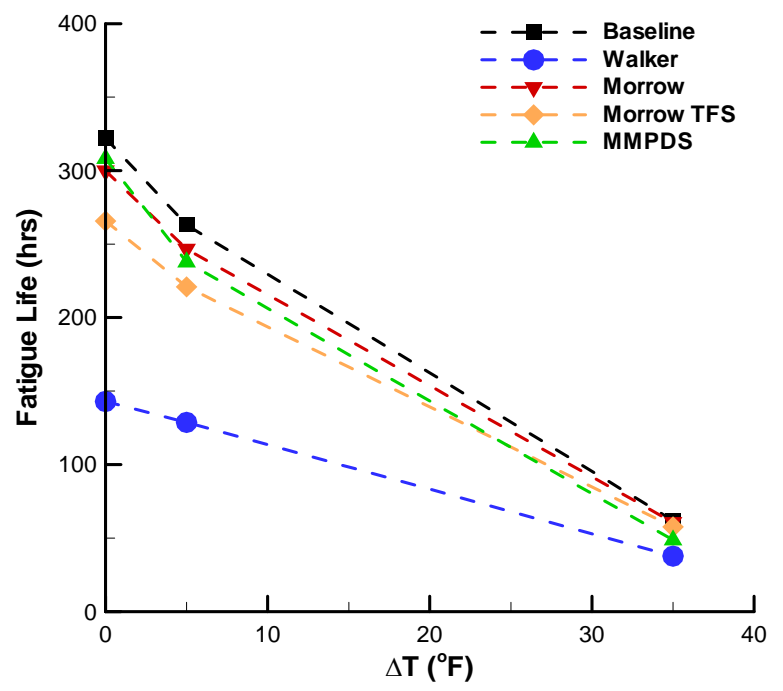

Figure 22: Clamped end fatigue estimates at 158dB.

As the acoustic excitation level is further increased to $170 \mathrm{~dB}$, stresses are sufficiently high to cause the material to yield in the clamped region. As previously noted in Figure 9, plasticity results in a compressive mean stress, which, when combined with the tensile membrane component, shifts the RFM toward the R $=-1$ main diagonal, as shown in Figure 23. While the low stress cycles now exhibit a compressive mean, the high stress cycles lie close to $R=-1$, due to the combined effect of material and geometric nonlinearity. The majority of accumulated damage consequently lies close or on $R=-1$. A comparison of the Walker and Morrow TFS RFD matrices, in Figure 24 and Figure 25, respectively, shows that the Morrow TFS model accumulate more damage than the Walker model. Recalling Figure 11 and Figure 12, this is also true of the baseline and Morrow. Only this MMPDS model is less conservative in this stress region. The corresponding fatigue life estimates are shown in Figure 26. Here the fatigue life estimates are within a factor of two, reflecting the fact that the difference in damage accumulation is less prevalent near $R=-1$. 


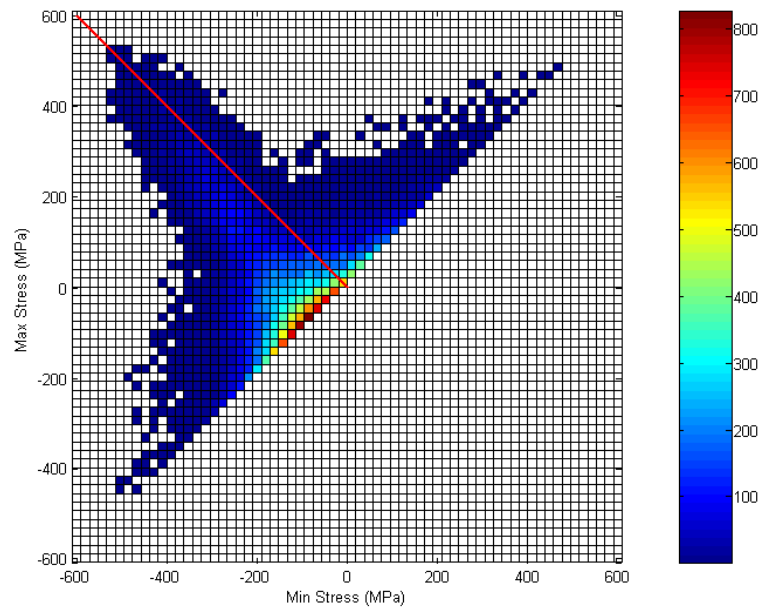

Figure 23: RFM for the $0^{\circ} \mathrm{F} / 170 \mathrm{~dB}$ condition.
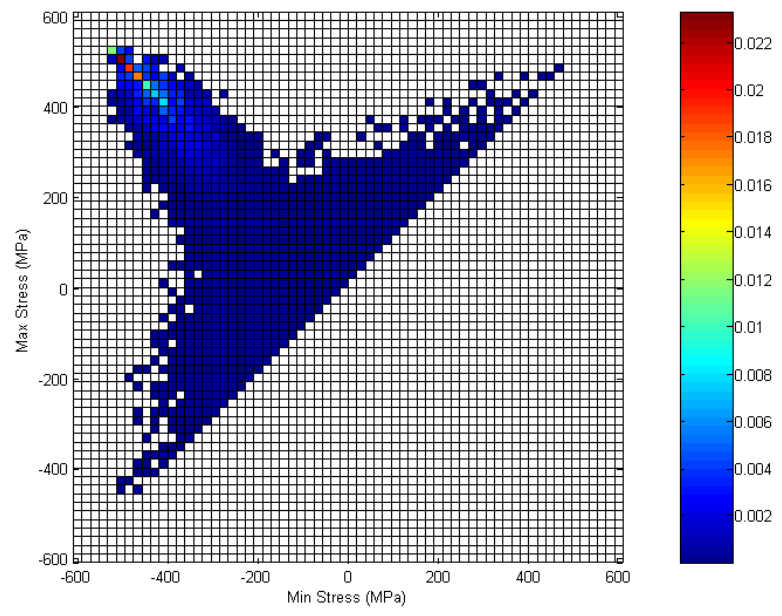

Figure 25: Morrow TFS model RFD for $0^{\circ} \mathrm{F} / 170 \mathrm{~dB}$.

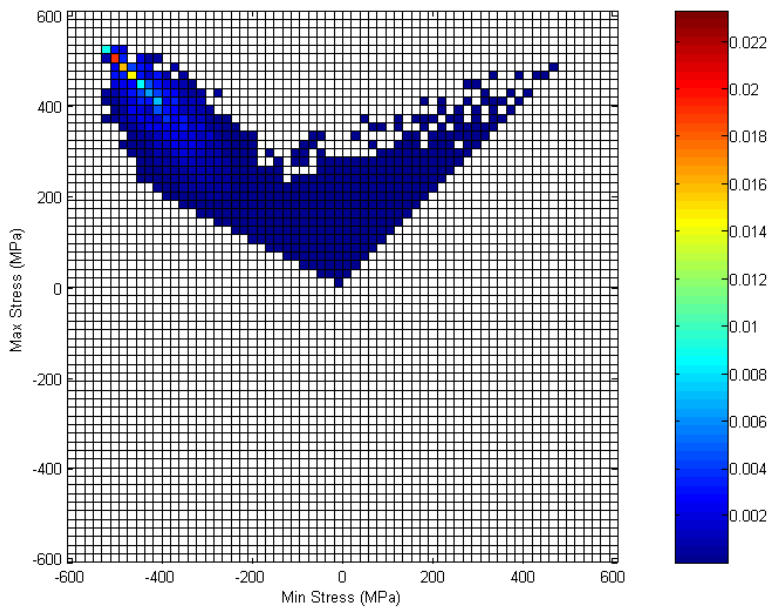

Figure 24: Walker model RFD for $0^{\circ} \mathrm{F} / 170 \mathrm{~dB}$.

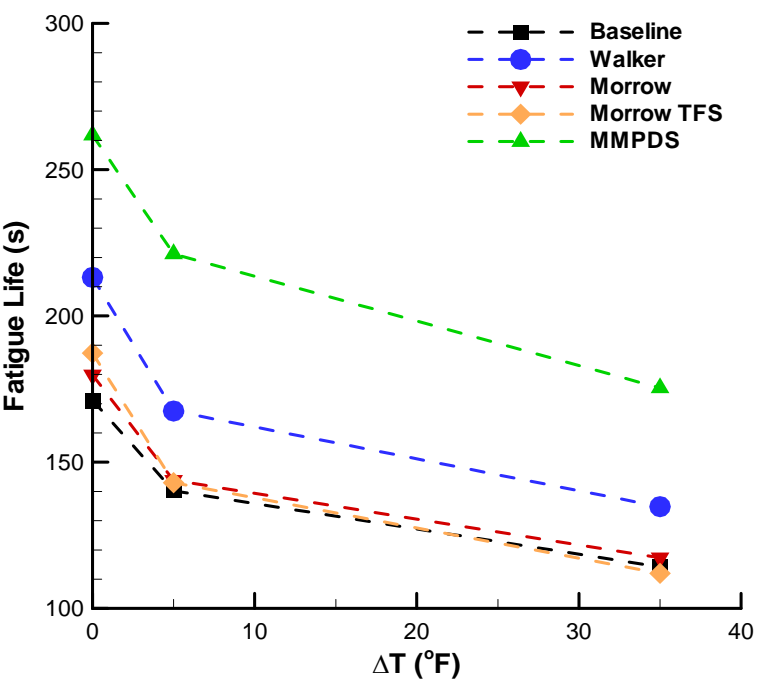

Figure 26: Clamped end fatigue estimates at $170 \mathrm{~dB}$.

Finally, in the pre-buckled configuration, there exists a compressive mean stress of approximately 57 MPa due to the thermal loading alone. Due to the dynamic loading, the structure responds in a geometrically nonlinear fashion and the mean stress diminishes. Like the plastic condition, this shifts the RFM to the left. However, the amplitude is not high enough to cause the peak stress region to move sufficiently close to $R=-1$ to make a significant difference in damage accumulation. Hence, the fatigue life estimates are similar to those noted in the unstressed reference condition, with Walker the most conservative in the linear elastic range, and Morrow, Morrow TFS, and baseline models more conservative in the plastic range. The fatigue life is reduced for this condition relative to the unstressed reference condition as the compressive stress causes the beam to become less stiff, resulting in a higher stress response for a given acoustic excitation level, see Figure 20, Figure 22, and Figure 26.

\section{Thermally Post-Buckled Condition}

The thermally post-buckled condition presents more interesting dynamic response behavior, resulting in either large amplitude oscillations about one of the equilibrium conditions, intermittent snap-through between equilibrium positions, or persistent snap-through between positions, as previously shown in Figure 5 and Figure 6.

Consider first the $35^{\circ} \mathrm{F} / 152 \mathrm{~dB}$ condition which results in large amplitude oscillations about one of the equilibrium positions. This is the only condition studied in which the top and bottom surfaces of the beam have differing time averaged stress responses. The RFM for the surface exhibiting a large tensile mean stress is shown in 
Figure 27. The opposing surface is in compression and will not dictate the fatigue life. Hence, it is not considered in the following. The mean stress puts the highest stress cycles in a region in which the Walker model is most conservative. This is clearly evident when comparing the Walker model RFD in Figure 28 with the Morrow TFS model RFD in Figure 29. The fatigue life estimates are shown in Figure 20 and indicate that the Walker model produces the most conservative fatigue estimates.

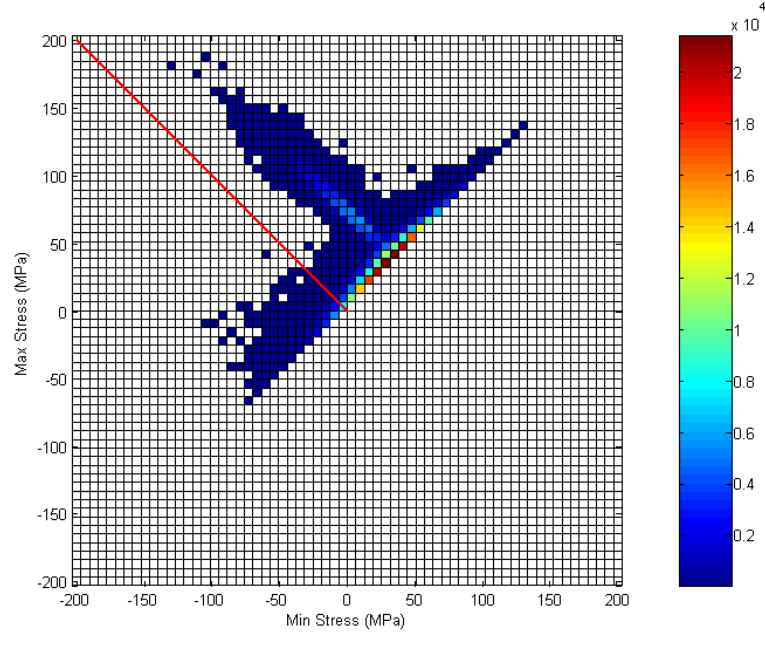

Figure 27: RFM for the $35^{\circ} \mathrm{F} / 152 \mathrm{~dB}$ condition.

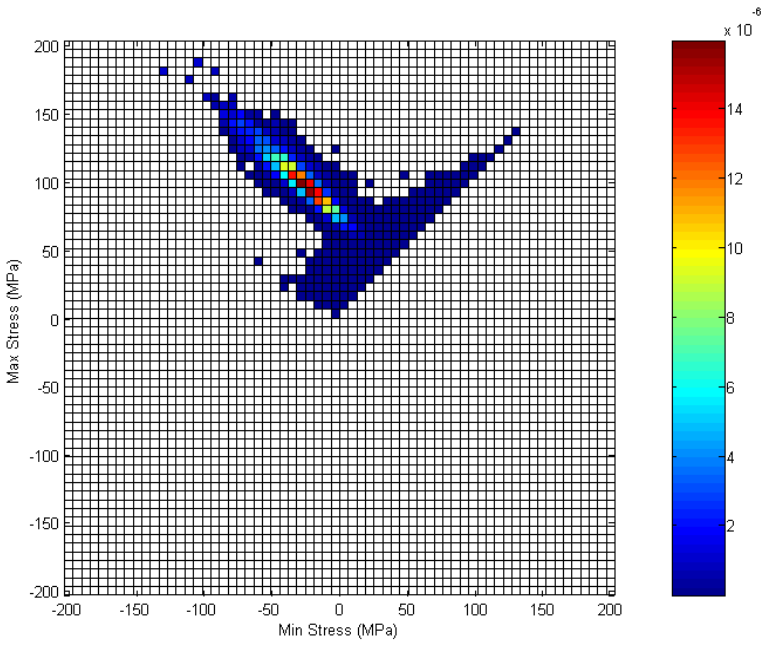

Figure 28: Walker model RFD for $35^{\circ} \mathrm{F} / 152 \mathrm{~dB}$.

As the sound pressure level increases to $158 \mathrm{~dB}$, the response enters into an intermittent snap-through motion between two symmetric equilibrium positions. This produces an RFM resembling a wishbone, as shown in Figure 30. Note that a single $59 \mathrm{~s}$ ensemble was used to generate this figure and the corresponding RFDs for clarity, but fatigue life estimates were made with 10 ensembles, as indicated in Section IV.A.

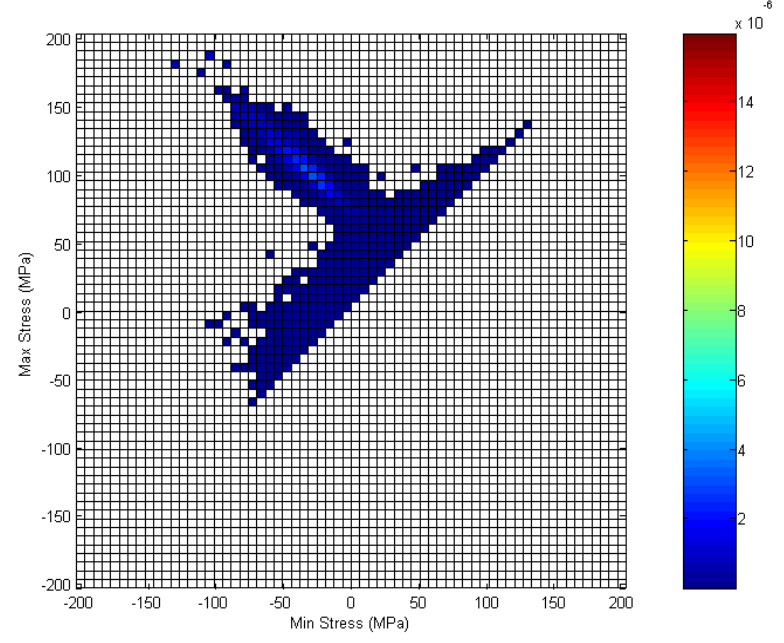

Figure 29: Morrow TFS model RFD for $35^{\circ} \mathrm{F} / 152 \mathrm{~dB}$.

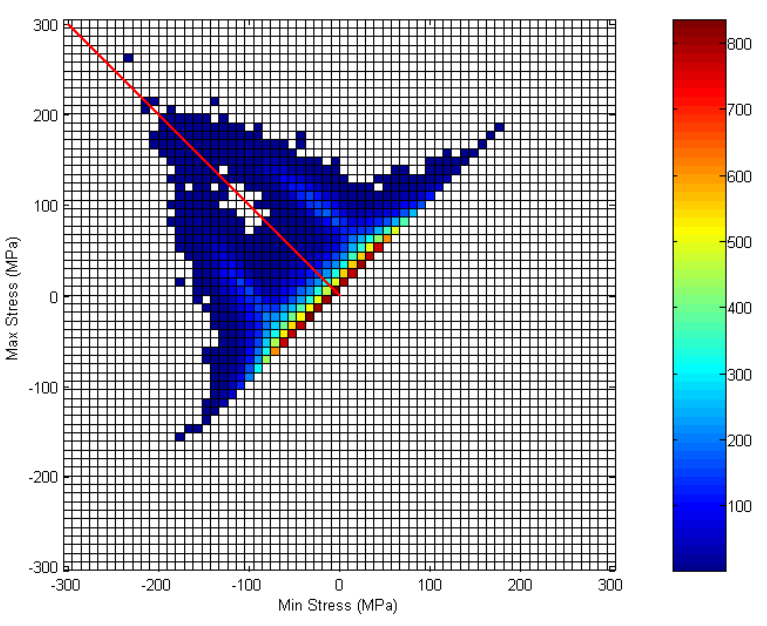

Figure 30: RFM for the $35^{\circ} \mathrm{F} / 158 \mathrm{~dB}$ condition.

Damage accumulation for the Walker and Morrow TFS models are shown in Figure 31 and Figure 32, respectively. Common to both models is a lack of damage accumulation associated with the lower equilibrium position (for the upper surface of the beam). Here the upper surface is in compression. The Walker model is seen to accumulate more damage for cycles oscillating about the upper equilibrium position than the Morrow TFS model, as was found to be the case for the $35^{\circ} \mathrm{F} / 152 \mathrm{~dB}$ condition. The most damaging events are associated with the large stress ranges as the structure snaps-through from one equilibrium position to the other. However, as this occurs only intermittently, most of the accumulated damage is still associated with oscillations about the upper position for the Walker model. Because of this, the Walker fatigue life estimate is still the most conservative of all the models, as shown in Figure 22. 


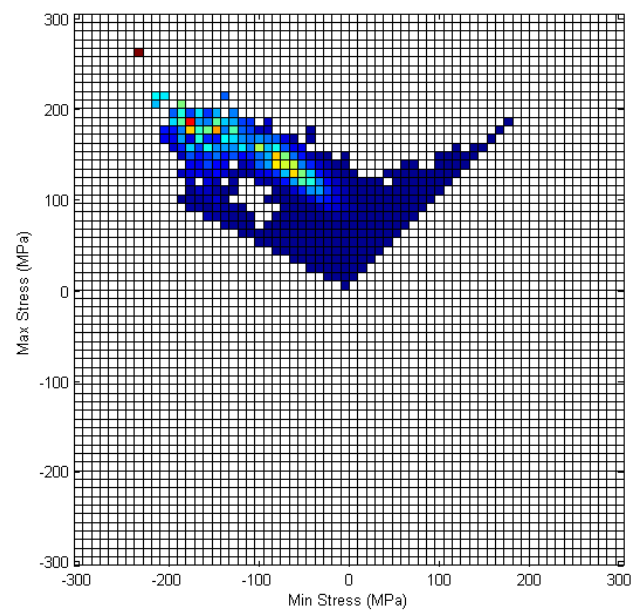

Figure 31: Walker model RFD for $35^{\circ} \mathrm{F} / 158 \mathrm{~dB}$

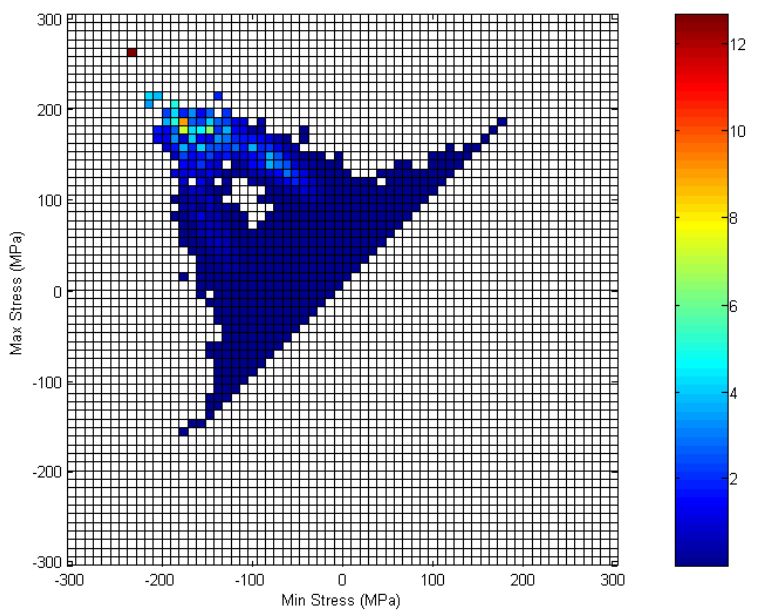

Figure 32: Morrow TFS model RFD at $35^{\circ} \mathrm{F} / 158 \mathrm{~dB}$.

Lastly, consider the $35^{\circ} \mathrm{F} / 170 \mathrm{~dB}$ condition. Here, the stress ranges which lie between the equilibrium positions are filled in by persistent snap-through motion, as shown in Figure 33. The RFM is much broader than either the $0^{\circ} \mathrm{F} / 170 \mathrm{~dB}$ or $35^{\circ} \mathrm{F} / 170 \mathrm{~dB}$ conditions because of the oscillations about the two equilibrium conditions. However, because of plasticity, the maximum stress is only slightly higher than either of those conditions. The broadness of the RFM is not significant however, as the majority of damage is along the fully reversed bending line $R=-1$. Here, as in previous $170 \mathrm{~dB}$ conditions, the damage accumulated by the Morrow TFS model is greater than that of the Walker model, as shown in Figure 34 and Figure 35. The fatigue estimates for all models are shown in Figure 26.

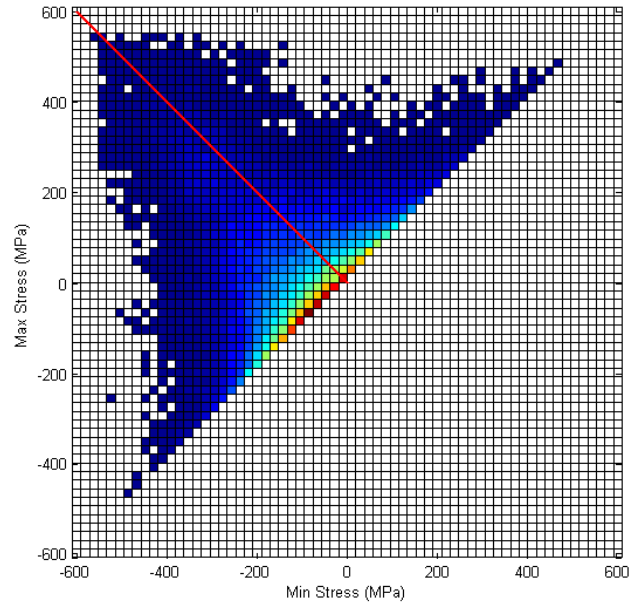

Figure 33: RFM for the $35^{\circ} \mathrm{F} / 170 \mathrm{~dB}$ condition.

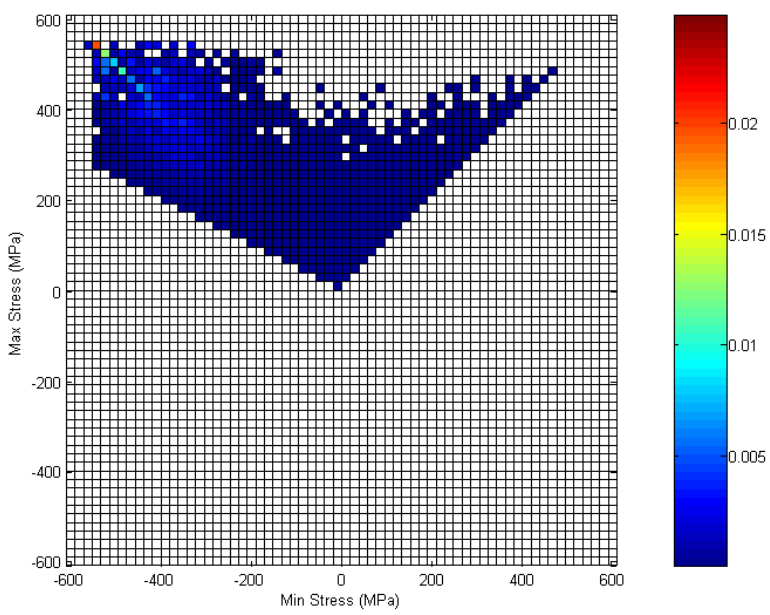

Figure 34: Walker model RFD for $35^{\circ} \mathrm{F} / 170 \mathrm{~dB}$.

Fatigue estimates made for the quarter-span location at shown in Figure 36, Figure 37, and Figure 38 for $152 \mathrm{~dB}$, $158 \mathrm{~dB}$, and $170 \mathrm{~dB}$ loadings, respectively. Because the stress is lower at the quarter-span than at the clamped end, all loading conditions indicate longer fatigue lives than the clamped end counterparts. In all but the $170 \mathrm{~dB}$ case, the stress is below the MMPDS endurance limit, and therefore MMPDS estimates are not available for the majority of conditions. Because of geometric nonlinearity, the tensile mean makes the Walker model produce the most conservative estimates. Unlike the clamped end, the quarter-span does not yield under any of the $170 \mathrm{~dB}$ conditions. Therefore, there is no compressive mean from material nonlinearity to offset the tensile mean from the geometric nonlinearity. A slight rise is seen in the Walker model estimate at the $5^{\circ} \mathrm{F} / 152 \mathrm{~dB}$ condition. For this condition, there is a compressive mean stress. As the compressive stress increases, all models except the baseline model accumulate less damage for a given amplitude. The rate at which this trend occurs is much higher for the Walker model than for the other models. It is seen that the differences in fatigue life between the various models at the 
quarter-span are smaller than the differences observed at the clamped end for all three conditions with $35^{\circ} \mathrm{F}$ temperature increments.

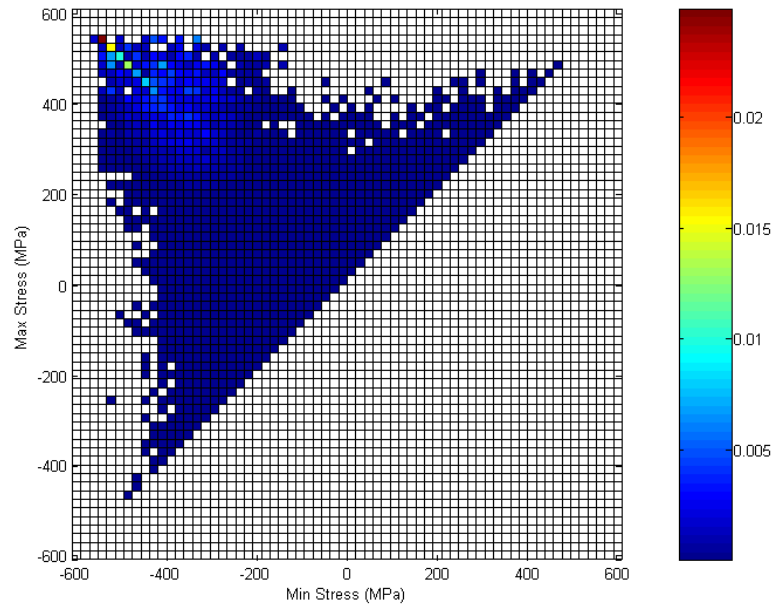

Figure 35: Morrow TFS model RFD for $35^{\circ} \mathrm{F} / 170 \mathrm{~dB}$.

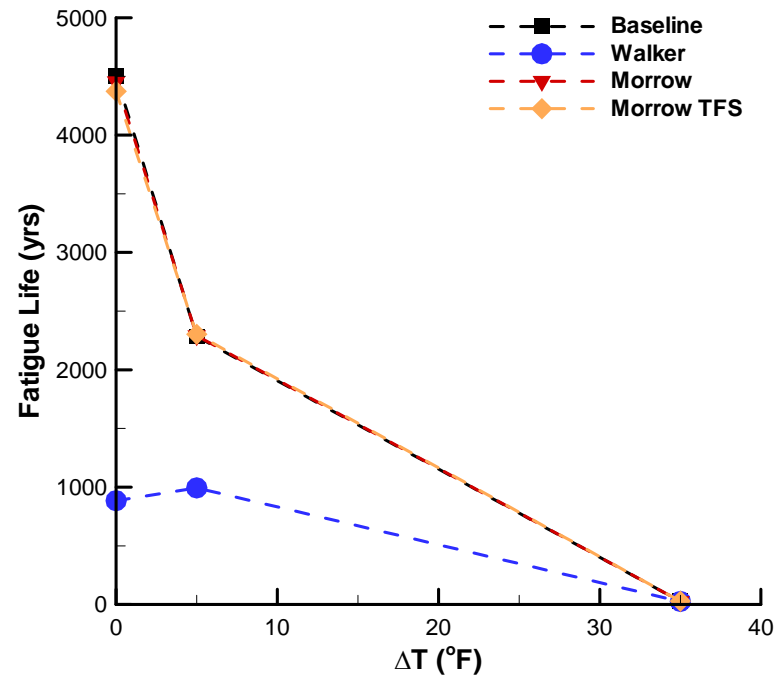

Figure 36: Quarter-span fatigue estimates at $152 \mathrm{~dB}$.

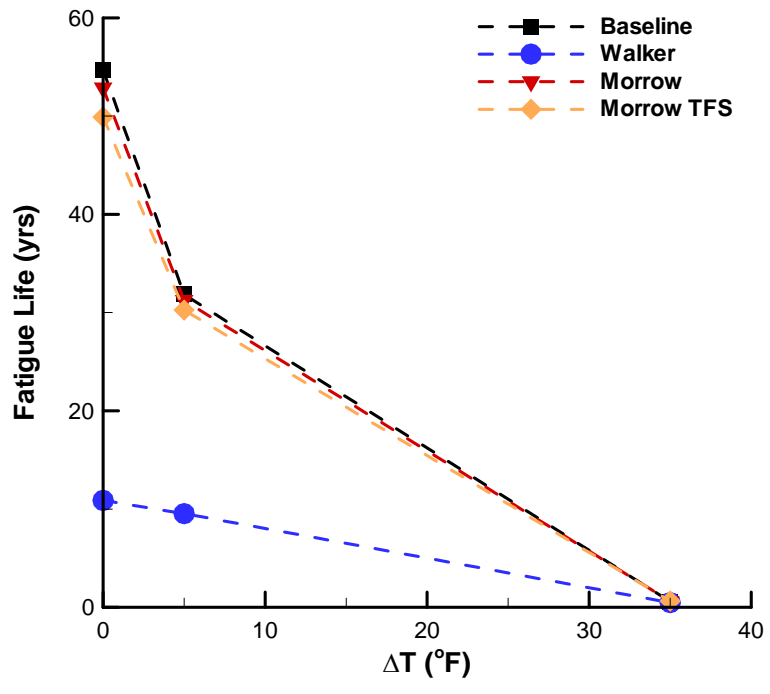

Figure 37: Quarter-span fatigue estimates at $158 \mathrm{~dB}$.

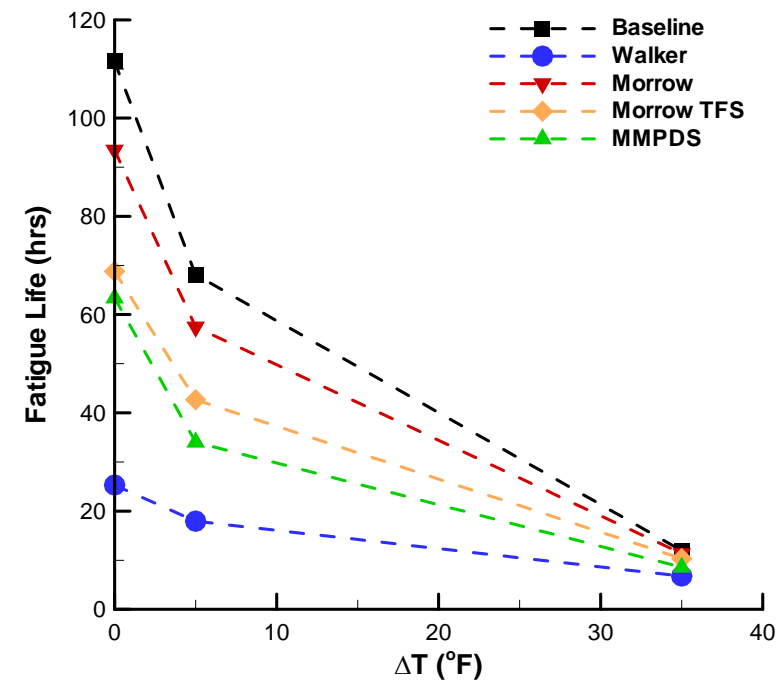

Figure 38: Quarter-span fatigue estimates at $170 \mathrm{~dB}$.

\section{Effect of Localized Material Nonlinearity}

The ratios between fatigue estimates obtained with the elastic material model and estimates obtained with the elastic-plastic material model are presented in Table 2 for all three $170 \mathrm{~dB}$ conditions at the quarter-span and clamped end. It is seen that the elastic-plastic material model generally yields longer fatigue estimates than the fully elastic model. Only two estimates made with the baseline model $\left(5^{\circ} \mathrm{F}\right.$ and $\left.35^{\circ} \mathrm{F}\right)$ indicate a slightly longer life for the elastic material model. Thus, material nonlinearity has a beneficial effect of limiting high amplitude stress cycles, albeit with the detrimental effect of permanent plastic deformation. Because the quarter-span location remained in the elastic response regime, material nonlinearity did not directly limit the stress in this location. Instead, the benefit was a result of a reduction in the dynamic response due to yielding nearer to the clamped end. This conclusion is borne out in Table 2, which shows a greater reduction in elastic model fatigue life at the clamped end, where both local plasticity and global dynamics are contributors, than at the quarter-span where only global dynamics contribute. Compare, for example, the Walker model at ambient conditions which indicates at clamped end fatigue life ratio of 0.360 , while the quarter-span ratio is 0.799 . 
Table 2: Fatigue estimates obtained with elastic material model at $170 \mathrm{~dB}$.

\begin{tabular}{|c|c|c|c|c|c|c|}
\hline \multirow{2}{*}{\multicolumn{2}{|c|}{$\begin{array}{l}\Delta T \text { and } \\
\text { Location }\end{array}$}} & \multicolumn{5}{|c|}{$\begin{array}{c}\text { Fatigue Life Ratio } \\
\text { Elastic Material Model / Elastic-Plastic Material Model }\end{array}$} \\
\hline & & Baseline & Walker & Morrow & Morrow TFS & MMPDS \\
\hline \multirow{2}{*}{$0^{\circ} \mathrm{F}$} & $\mathrm{CL}$ & 0.638 & 0.360 & 0.436 & 0.219 & 0.519 \\
\hline & $\mathrm{Q}$ & 0.815 & 0.799 & 0.789 & 0.741 & 0.562 \\
\hline \multirow{2}{*}{$5^{\circ} \mathrm{F}$} & $\mathrm{CL}$ & 0.935 & 0.557 & 0.688 & 0.411 & 0.684 \\
\hline & $\mathrm{Q}$ & 1.013 & 0.997 & 0.991 & 0.952 & 0.871 \\
\hline \multirow{2}{*}{$35^{\circ} \mathrm{F}$} & $\mathrm{CL}$ & 0.608 & 0.410 & 0.450 & 0.240 & 0.396 \\
\hline & $\mathrm{Q}$ & 1.025 & 0.903 & 0.992 & 0.935 & 0.877 \\
\hline
\end{tabular}

\section{Conclusions}

Five distinct high-cycle fatigue models were considered in the analysis of an aluminum beam subjected to combined thermal-acoustic loadings. Four of the models accounted for the presence of mean stress, and one neglected this effect. The structural dynamic response regimes included an unstressed reference condition, a prebuckled condition, and a thermally post-buckled condition which permitted snap-through behavior. A broadly applicable methodology was developed to determine the most conservative fatigue model through an understanding of how each model accumulates damage as a function of the mean stress. For the specific problem considered, it was found that the Walker model provided the most conservative fatigue estimate when the stress response had a tensile mean due to the effect of geometric nonlinearity alone. For sufficiently high loading conditions, the Morrow and Morrow TFS models were found to produce the most conservative estimates in locally plastic regions. These conditions were characterized by the most damaging stress cycles being fully reversed. Although not generally recommended for nonlinear response problems, the zero-mean baseline model was coincidentally found to produce conservative estimates for the high loading conditions. Local plasticity was determined to be beneficial to fatigue life relative to the elastic material model. Additional work is needed to generalize the specific conclusions for other material systems, structural configurations, and loading conditions.

\section{References}

${ }^{1}$ Mei, C., Dhainaut, J.M., Duan, B., Spottswood, S.M., and Wolfe, H.F., "Nonlinear random response of composite panels in an elevated thermal environment," Air Force Research Laboratory AFRL-VA-WP-TR-2000-3049, WPAFB, OH, 2000.

${ }^{2}$ Przekop, A. and Rizzi, S.A., "Dynamic snap-through response of thin-walled structures by a reduced order method," Proceedings of the 47th AIAA/ASME/ASCE/AHS/ASC Structures, Structural Dynamics and Materials Conference, AIAA-2006-1745, Newport, RI, 2006.

${ }^{3}$ Murphy, K.D., Virgin, L.N., and Rizzi, S.A., "Experimental snap-through boundaries for acoustically excited, thermally buckled plates," Experimental Mechanics, Vol. 36, No. 4, 1996, pp. 312-317.

${ }^{4} \mathrm{Ng}$, C.F., "Nonlinear and snap-through responses of curved panels to intense acoustic excitation," Journal of Aircraft, Vol. 26, No. 3, 1989, pp. 281-288.

${ }^{5} \mathrm{Ng}$, C.F. and Clavenson, S.A., "High-intensity acoustic tests of a thermally stressed plate," Journal of Aircraft, Vol. 28, No. 4, 1991, pp. 275-281.

${ }^{6}$ Rizzi, S.A. and Przekop, A., "Estimation of sonic fatigue by reduced-order finite element based analyses," Structural Dynamics: Recent Advances, Proceedings of the 9th International Conference, Southampton, UK, 2006, M.J. Brennan, et al. (ed.).

7"Metallic Materials Properties Development and Standardization (MMPDS-01)," U.S. Department of Transportation, Knovel Interactive Edition, 2004.

8"ABAQUS version 6.6 On-line Documentation, ABAQUS Analysis User's Manual, Section 6.3.3 " Abaqus, Inc., 2005.

${ }^{9}$ Rizzi, S.A. and Muravyov, A.A., "Comparison of nonlinear random response using equivalent linearization and numerical simulation," Structural Dynamics: Recent Advances, Proceedings of the 7th International Conference, Vol. 2, Southampton, UK, 2000, N.S. Ferguson, et al. (ed.), pp. 833-846.

${ }^{10}$ Dowling, N.E., "Mean stress effects in stress-life and strain-life fatigue," Fatigue 2004: Second SAE Brasil Conference on Fatigue, SAE 2004-01-2227, São Paulo, Brasil, 2004.

${ }^{11}$ Miner, M.A., "Cumulative damage in fatigue," Trans. ASME, Journal of Applied Mechanics, Vol. 67, No. 1945, pp. A159A164.

${ }^{12}$ Sweitzer, K.A. and Ferguson, N.S., "Mean stress effects on random fatigue of nonlinear structures," XII International Congress on Sound and Vibration, Lisbon, Portugal, 2005.

13"WAFO - A Matlab toolbox for analysis of random waves and loads," Version 2.1.1, The WAFO Group, Lund Institute of Technology, Lund University, 2005.

${ }^{14}$ Sweitzer, K.A. and Ferguson, N.S., "Estimating nonlinear random response statistics," Structural Dynamics: Recent Advances, Proceedings of the 9th International Conference, Southampton, UK, 2006, M.J. Brennan, et al. (ed.), The Institute of Sound and Vibration Research, University of Southampton. 